NIST

PUBLICATIONS
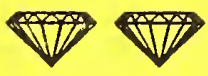

\title{
Workshop on Characterizing \\ Diamond Films
}

\section{February 27, 28, 1992 Gaithersburg, MD}

\author{
Albert Feldman \\ National Institute of Standards \\ and Technology \\ Charles P. Beetz \\ Advanced Technology Materials \\ Michael Drory \\ Crystallume \\ Sandor Holly \\ Rockwell International
}

U.S. DEPARTMENT OF COMMERCE

Technology Administration

National Institute of Standards

and Technology

Ceramics Division

Materials Science and Engineering Laboratory

Gaithersburg, MD 20899 



\title{
Workshop on Characterizing Diamond Films
}

\section{February 27, 28, 1992 Gaithersburg, MD}

\author{
Albert Feldman \\ National Insktitute of Standards \\ and Technology \\ Charles P. Beetz \\ Advanced Technology Materials

\section{Michael Drory \\ Crystallume}

\section{Sandor Holly \\ Rockwell International}

\author{
U.S. DEPARTMENT OF COMMERCE \\ Technology Administration \\ National Institute of Standards \\ and Technology \\ Ceramics Division \\ Materials Science and Engineering Laboratory \\ Gaithersburg, MD 20899
}

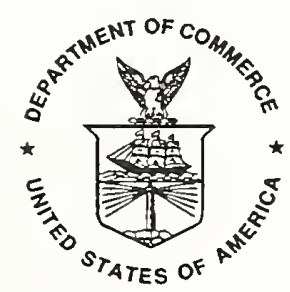

U.S. DEPARTMENT OF COMMERCE Barbara Hackman Franklin, Secretary

TECHNOLOGY ADMINISTRATION

Robert M. White, Under Secretary for Technology

NATIONAL INSTITUTE OF STANDARDS

AND TECHNOLOGY

John W. Lyons, Director 

Organizing Committee:

Chairman - Albert Feldman, NIST Sandor Holly, Rockwell International Charles Beetz, Advance Technology Materials Michael Drory, Crystallume 



\section{CONTENTS}

$\begin{array}{ll}\text { ABSTRACT } & 1\end{array}$

INTRODUCTION AND CONCLUSIONS 3

THERMAL PROPERTIES MEASUREMENTS 4

MECHANICAL PROPERTIES 6

THE NEED FOR STANDARDS

REFERENCES 9

APPENDIX A - Invitation Letter and Planning Form 10

$\begin{array}{ll}\text { APPENDIX B - Workshop Evaluation } & 13\end{array}$

$\begin{array}{ll}\text { APPENDIX C - Workshop Program } & 17\end{array}$

$\begin{array}{ll}\text { APPENDIX D - Abstracts } & 20\end{array}$

APPENDIX E - Company Presentation Materials 51

APPENDIX F - List of Attenders 88 



\begin{abstract}
A workshop was held at NIST on February 27th and 28th to discuss specific topics deemed important to the characterization of diamond films made by chemical vapor deposition and to address the need for standards in diamond technology. The workshop was held in response to a recommendation in a recent report assessing diamond technology in Japan [1]. The audience targeted for this workshop were the producers and potential users of CVD diamond technology in the United States. University scientists were invited as experts in property measurements. There were 35 attenders at the workshop. The workshop consisted of presentations in the areas of thermal conductivity measurement, mechanical properties measurement, and the need for standards.
\end{abstract}

Key words: chemical vapor deposition, CVD, diamond, mechanical properties, Raman spectroscopy, standards, thermal conductivity. 



\section{WORKSHOP ON CHARACTERIZING DLAMOND FILMS}

\section{Introduction and Conclusions}

A workshop was held at NIST on February 27th and 28th to discuss specific topics deemed important to the characterization of diamond films made by chemical vapor deposition (CVD) and to address the need for standards in diamond technology. The workshop was held as a follow-up to a recommendation in a recent report assessing diamond technology in Japan [1]. The audience targeted for this workshop were the producers and potential users of CVD diamond technology in the United States. University scientists were invited as experts in properties measurements. There were 35 attenders at the workshop.

The workshop consisted of two components, technical presentations by active researchers on topics of the most immediate relevance to commercial applications and presentations by companies describing their needs for standards.

Rather than choose a wide variety of topics for discussion, we focussed on two technical topics, the measurement of thermal conductivity or thermal diffusivity for heat dissipation applications, and the measurement of mechanical properties of diamond for cutting tool applications. These properties are important for other applications as well. The topics were selected on the basis of responses to a letter sent to potential attenders of the workshop. (See Appendix A for a copy of the letter, the reply form, and a summary of the responses.) Presentations describing the NIST Advanced Technology Program and NIST facilities that might be useful to diamond researchers were also given.

After the workshop, an evaluation form was sent to all registrants. The purpose of the form was to determine the usefulness of the workshop, the desire for further workshops, and the need for standards related activities. A copy of this questionnaire and the results are summarized in Appendix B.

Sections 2 to 4 contain summaries of the three main sessions of the workshop. Appendix C contains the workshop Program, Appendix D contains abstracts of the papers presented, Appendix $\mathrm{E}$ contains copies of presentation materials provided by company presenters, and Appendix $F$ contains a list of the attenders.

The principal conclusions to be drawn from the workshop include:

- There is a need to standardize characterization methods so that experimental data, measured at different sites by different workers, may be meaningfully compared. 
- There is a need for specimens with well characterized properties. The first priority identified was a need for specimens to measure thermal conductivity or thermal diffusivity in interlaboratory round-robin comparisons. Development of a Raman standard reference material would also be useful for assessing diamond quality.

Standards for mechanical measurements would be premature at present. Only a limited number of measurements of specific properties, such as fracture toughness and hardness, have been made. Because of the great hardness of diamond, mechanical measurements are difficult to make and difficult to interpret.

Other workshops should be held at intervals of about one year, focussing on other topics, such as optical and electrical properties.

Working groups dealing with standards for specific topical areas should be established, possibly under the auspices of a standards organization such as ASTM.

NIST has an important role to play in coordinating and facilitating the development of standards for diamond technology and in developing standard reference materials.

\section{Thermal Properties Measurement}

The session on thermal properties consisted of eight speakers presenting different measurement techniques.

The first paper was given by J. Graebner from AT\&T Bell Laboratories. He gave a brief review of the physical mechanisms responsible for thermal conduction in diamond and then discussed measurements of thermal conductivity he has made on natural single crystal diamonds and on CVD diamond films. Results of thermal conductivity measurements obtained with three different techniques were presented. Dr. Graebner showed that the thermal conductivity varied through the thickness dimension of a CVD diamond film; the bottom surface, the surface where film growth began, had one fourth the thermal conductivity of the top surface. Moreover, the thermal conductivity was anisotropic; the thermal conductivity for heat flow parallel to the specimen surfaces was lower than the thermal conduction for heat flow perpendicular to the specimen surfaces. In a film $300 \mu \mathrm{m}$ thick the thermal conductivity near the top surface was found to be 22 $\mathrm{W} \cdot \mathrm{cm}^{-1} \cdot \mathrm{K}^{-1}$, which is comparable to the value for high quality single crystal diamonds. By modeling the dependence of the thermal conductivity on grain size, he predicted thermal conductivity of $25-28 \mathrm{~W} \cdot \mathrm{cm}^{-1} \cdot \mathrm{K}^{-1}$ for $1 \mathrm{~mm}$ sized grains, an interesting result because these values are unexpectedly large. 
The second speaker was J. Vandersande from the Jet Propulsion Laboratory, who discussed the temperature dependence of the thermal conductivity of white natural diamonds. Thermal diffusivity measurements were made from room temperature to $1000 \mathrm{~K}$ by means of a flash lamp measurement technique. The room temperature thermal conductivity was $23 \mathrm{~W} \cdot \mathrm{cm}^{-1} \cdot \mathrm{K}^{-1}$ and at $1200^{\circ} \mathrm{C}$ was $5 \mathrm{~W} \cdot \mathrm{cm}^{-1} \cdot \mathrm{K}^{-1}$. This technique can also be used to measure the specific heat. As an aside, Dr. Vandersande demonstrated that due to instrumentation limitations, the true electrical resistivity of diamond can be much larger than measurements would indicate.

D. Cahill from the University of Illinois discussed measuring thermal conductivity by an AC measurement technique, called the three-omega method. In this method, a thin metal wire is deposited onto the diamond surface. The wire with electrical resistance, $R$, acts both as the heat source and as the thermometer. An alternating current, I, produces resistive heating, $I^{2} R$; the resultant temperature rise in the specimen produces a change in resistance of the wire. This change in resistance is a measure of the temperature. The technique is called the three-omega method because the measurements are made at the third harmonic of the AC current frequency. This technique is immune to the effects of thermal radiation and is well suited for measurements both on bulk specimens or on thin films. Dr. Cahill measured the thermal conductivity of a range of carbon based materials, including $\mathrm{C}_{60}$; the values spanned four orders of magnitude.

R. Tye, a consultant to Sinku-Riko, discussed a commercially available instrument that uses a modified AC calorimetry method based on optical heating to measure both the thermal diffusivity and the heat capacity of thin films. Dr. Tye showed results for diamond films and for standard samples of nickel, silicon, alumina and stainless steel.

D. Morelli of the General Motors Research Laboratories showed how thermal conductivity measurements can be used to study defects in diamond. He reviewed the sources of error in the classic steady state method of measuring thermal conductivity. Results of thermal conductivity measurements conducted over a range of temperatures down to cryogenic temperatures on films deposited by plasma assisted CVD and hot filament CVD were reported. Although the films prepared by the two methods were alike in almost all respects, the films prepared by the hot filament method showed an anomalous behavior at low temperature that has not yet been explained.

P.K. Kuo of Wayne State University discussed the measurement of the thermal diffusivity of diamond by the method of photothermal deflection. In this technique, a probe laser beam skimming the surface of the specimen is deflected by refractive index gradients that occur in the air above the specimen due to heating from a thermal wave propagating in the specimen. Results were reported for diamond films down to $5 \mu \mathrm{m}$ thick and for synthetic single crystal diamonds about $3.5 \mathrm{~mm}$ thick. Values of thermal 
diffusivities ranged from less than $1 \mathrm{~cm}^{2} \cdot \mathrm{s}^{-1}$ to $9.2 \mathrm{~cm}^{2} \cdot \mathrm{s}^{-1}$. Dr. Kuo also discussed a modification to the technique in which the probe beam passes directly through the crystal under measurement.

G. Lu from the Norton Company discussed the requirements for a measurement technique that could be used effectively as a process monitor or a quality control monitor. First he described the converging thermal wave technique that he uses to measure thermal diffusivity. Then he discussed the results of a thermal conductivity round-robin, in which diamond samples taken from a contiguous section of a $10 \mathrm{~cm}$ diameter diamond plate were sent to several laboratories for thermal conductivity measurements. Each laboratory used a different method of measurement. The values of thermal conductivity displayed considerable scatter, generally ranging from 12.3 to $16.7 \mathrm{~W} \cdot \mathrm{cm}^{-1} \cdot \mathrm{K}^{-1}$ with one result greater than $20 \mathrm{~W} \cdot \mathrm{cm}^{-1} \cdot \mathrm{K}^{-1}$. The cause of the scatter in the data was discussed but not resolved.

A. Feldman from NIST discussed the use of photothermal radiometry for measuring the thermal diffusivity of diamond. Two different geometries for making the measurement were discussed, one using a laser heating beam with a cylindrically symmetric Gaussian profile and another using a laser heating beam with a cylindrically symmetric ring profile which results from placing an axicon lens into the beam. The results of numerical simulations for the phase and magnitude of the surface temperature as a function of the chopping frequency of the laser were presented. He also discussed the importance of knowing the laser beam characteristics and the importance of having the sample precisely focussed on the detector.

\section{Mechanical Properties}

Characterizing the mechanical properties of CVD diamond requires that several broad topical areas be explored. These include elastic properties, plastic properties, and fracture properties.

In the case of a composite system, such as diamond/silicon, interface properties are an additional consideration. Examples of elastic properties to be examined include Young's modulus and Poisson's ratio. The hardness is a primary measure of plastic behavior, while fracture toughness characterizes the fracture behavior of a material. In this workshop, each broad area of mechanical behavior was briefly considered for the purpose of assessing the status of testing methods and practices in preparation for standards. As described below, several areas of mechanical characterization of CVD diamond are generally unexplored, requiring considerably more attention in coming years.

Of the mechanical properties, the elastic behavior of CVD diamond has received the most attention by researchers because of the potential benefits diamond brings to window applications. Recent work on the elastic properties of CVD diamond was 
presented by C.A. Klein of Raytheon in which attention was directed toward the elastic constants of polycrystalline diamond derived from single crystal values. Dr. Klein emphasized the considerable range in measured values of Young's modulus obtained by different researchers. He pointed out the need for careful sample description and careful analysis of the test method. In addition, he pointed out that the Poisson's ratio should be 0.07 rather than the 0.2 , the latter value being often cited in the literature.

Considerable work has been done on the plastic behavior of CVD diamond. Presentations by C.V. Cooper of United Technologies and C.J. McHargue of the University of Tennessee discussed the use of nanoindentation to obtain the hardness of CVD diamond. The dependence of hardness on process variables, such as the amount of methane in the deposition feed gas, were discussed. Dr. Cooper discussed the experimental difficulties caused by surface roughness. Dr. McHargue discussed the experimental difficulties associated with the choice of indenter geometry. Dr. McHargue also pointed out the necessity of relating a particular test procedure to a specific definition of hardness.

The fracture behavior of CVD diamond was discussed in several of the presentations. J.J. Mecholsky of the University of Florida and P. Klocek of Texas Instruments discussed the measurement of the film fracture toughness by means of a surface analysis technique, while M.D. Drory discussed an indentation method. Professor Mecholsky's method showed considerable potential for determining the fracture toughness for a variety of specimen geometries, without the need for special specimen preparation.

M.D. Drory discussed quantifying adhesion through the measurement of interface fracture toughness. In particular, a first-order analysis was presented for determining interface toughness from a brale indentation measurement. The test was applied to diamond on relatively ductile substrates, such as cemented carbide. Considerably more work is needed to develop adhesion tests suitable to diamond.

\section{The Need for Standards}

There are several good reasons to establish standards for the evolving field of CVD diamond film technology. One of the purposes of this workshop was to identify the needs for standards in industry. Representatives of six companies agreed to discuss their views on this subject. The speakers were J.W. Mitchell of AT\&T Bell Laboratories, M.D. Drory of Crystallume, K. Gray of Norton Diamond Films, S. Holly of Rockwell International, P. Klocek of Texas Instruments and C.J. Robinson of the Raytheon Company. All of the companies are currently conducting CVD diamond film research. While some of the companies are commercial producers of the material, others are users of CVD diamond and are applications oriented.

The presentations described the current methods of characterizing diamond films used by these companies and the importance of the measurements to quality assurance of the 
CVD diamond material as related to a variety of company specific applications. The most important application areas discussed were thermal (heat sinks), optical (infrared windows and domes), tribiological, and electronic.

All of the presenters agreed on the value of standards to meet performance criteria in different applications. There is a need to standardize the characterization methods so that experimental data, measured at different sites by different workers, may be meaningfully compared. To that end, a discussion began on the value of round-robin type tests, where the same sample is measured by different laboratories, often using different measuring methods. The importance of thorough documentation of the methods used in these measurements was emphasized. In fact, the question of what "thorough documentation" means directly emphasized the need for standards, the focus of this workshop.

It became obvious during these discussions that different applications require different types of measurements. There was also a general consensus that measurements procedures bridging different disciplines are needed. Because of the interdisciplinary requirements of the technology, the activities of workers with different areas of expertise will require coordination. These workshops provide such a forum.

It may be practical or it may even be necessary to form specialty groups to formulate standards in separate application areas. Development of standards would start with the definition of simple concepts, such as the meaning of 'high quality diamond' and the interpretation of a particular characterization, such as a Raman spectrum or a thermal conductivity measurement.

In order for the industrial community to derive immediate benefits from these standardization activities, it will be important to promote exchange of information through meetings and publications. It was also proposed that a data base of CVD diamond material properties, with data obtained by accepted "standardized" measurement methods, be established. The data base would require updating on a continual basis.

There was general agreement during the discussions in this session, that focussing on just one characteristic at a time was most valuable. The previous day's session on thermal properties, which contained technical papers describing methods of measuring thermal conductivity of CVD diamond, was an excellent example of the value and necessity of focussing on a single characteristic. Agreement was reached among many workshop participants, that future workshops on standardization should highlight other characteristics, such as optical or electrical properties.

A pertinent final presentation in this session was made by E.S. Etz of NIST who discussed development of a standard reference material for Raman spectroscopy of CVD diamond [2]. It was generally agreed that such a standard would be useful. Questions 
Questions to be considered are: how many specimens would be needed, how should the specimens be obtained, what specimen dimensions are needed, and how extensively should the specimens be characterized by other methods?

\section{References}

[1] NIST Special Publication 807, U.S. Assessment of the New Diamond Technology in Japan, (USGPO, 1991) edited by A. Feldman and L.H. Schwartz.

[2] E.S. Etz in Applications of Diamond Fulms and Related Materials, Y. Tzeng, M.

Yoshikawa, M. Murakawa, A. Feldman (Editors) Elsevier Science Publishers B.V., 1991. 
Appendix A. Invitation Letter and Planning Form.

The next two pages contain the letter and return form sent to potential attenders of the Workshop on Characterizing Diamond Films. The technical subjects were chosen on the basis of the returned response forms.

The following table summarizes the responses received.

RESPONSES

Thermal properties

Adhesion, Fracture toughness

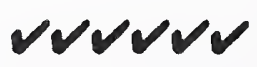

Hardness

Raman spectroscopy standard

Internal stress

Dopant concentration and distribution

Electrical properties

Electrical contacts

Impurity determination and distribution

Crystal perfection

Texture

Optical properties

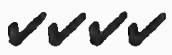

Thickness

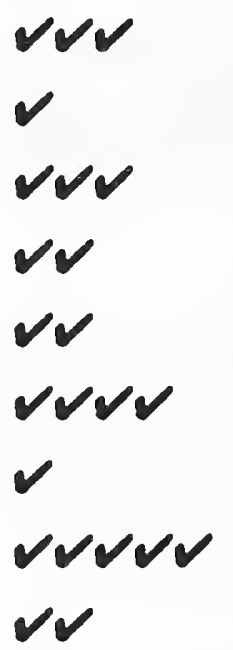


October 28, 1991

(name and address)

Dear Colleague:

NIST is planning a Workshop on Characterizing Diamond Films to be held February 27 and 28, 1992. It is intended to be the first of a series that will lead to consensus standards for producers and customers of products made of CVD diamond. This workshop is being organized by NIST because recent requests for information suggested that such a workshop would be appropriate. Your company, which has been identified as having an interest in CVD diamond technology, may benefit from such a workshop. The purpose of this letter is to request your input in planning the workshop.

The goal of this workshop is to bring together people from U.S. induntry with an intereat in the development of industrial or commercial diamond products and specialists in measurement methodologies for the purpose of discussing procedures to be used for measuring key diamond properties. As the marketplace for products made of CVD diamood develope, standardized measurement methods may be needed for obtaining properties that are essential for particular commercial applications. General objectives of the workshop include the discussion of nondestructive measurement methods, in-situ methods to measure and control key properties during material production and device fabrication, and measurement methods required by the unique properties of diamond. The application areas to which this workshop will be pertinent are mechanical, electrical, thermal, and optical. Many of the key properties may be relevant to more than one application area. Topics for discussion might include:

- Thermal properties

- Adhesion

- Hardness

- Raman spectroscopy standard

- Internal stress

- Dopant concentration and distribution

- Electrical properties

- Electrical contacts

- Impurity determination and distribution

- Crystal perfection

- Texture

- Optical properties

- Thickness

In order to better focus our efforts for in depth discussions within the allotted time, the scope of the workshop should be limited to perhaps three topical areas. I am therefore requesting that you or another representative from your company complete the attached form indicating your intention to attend the workshop, the topical areas you would like discussed and suggestions of experts you believe would aid our discussions. Also, please indicate whether a representative of your company is willing to discuss your involvement with diamond technology and your needs for standardized measurement procedures.

It is hoped that this workshop is the beginning of a process that will be continued by the CVD diamond community.

Sincerely,

Albert Feldman

Leader, Optical Materials Group

Ceramics Division

Materials Science and Engineering Laboratory

Tel: 301/975-5740, FAX: 301/990-8729 
Do you or does anyone from your company plan to attend this workshop? $\square$ yes $\square$ no

Number of attendees (Maximum of two)?

$\square$ one $\square$ two

NAMES, ADDRESSES and TELEPHONE NUMBERS of ATTENDEES

Name

Company and Address
Name

Company and Address
Telephone number

FAX number
Telephone number

FAX number

Please check up to three topical areas you consider most important and want discussed. Also, suggest any experts you feel would aid our discussions.

\section{Topics}

Expert

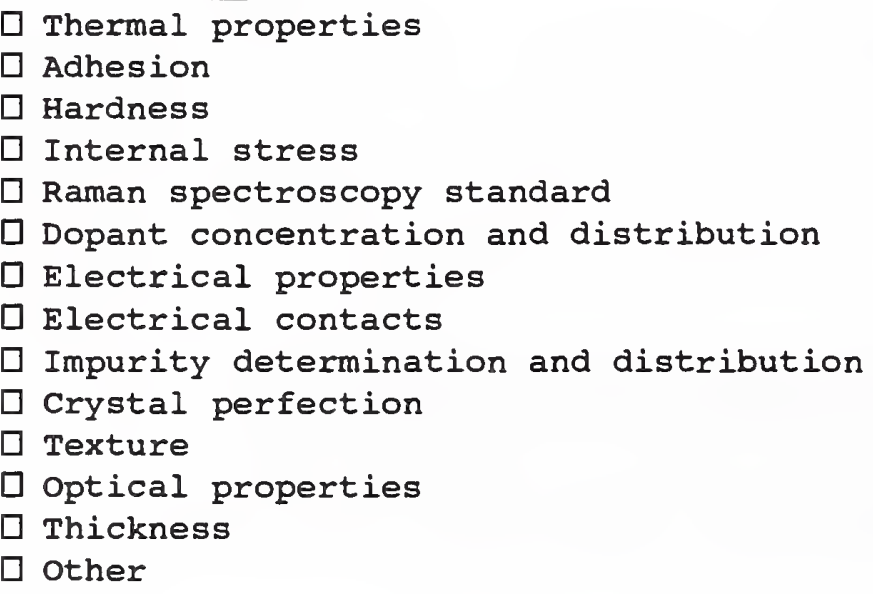


At the conclusion of the workshop, all of the participants were given an evaluation form to complete. A slightly modified form was sent as a reminder to those who did not complete their evaluation forms. A copy of the latter form is reproduced on the next two pages.

Table B1 summarized the responses to the most pertinent questions. The numbers labelling the columns correspond to the question numbers on the evaluation form. The responses to questions 1 through $2 b$ were converted to numerical scores range from -10 for not useful, to 0 for neutral, to 10 for very useful. Question 5 required four responses which are listed in order in the 5 column of Table B1.

The principal conclusions to be drawn from the responses, in the order given in Table $1 \mathrm{~B}$ are:

1. The workshop was generally usefull to very useful for the great majority of respondents.

2a. Another workshop covering the same topics would not be as useful. The university attenders were more positive about covering the same topics, most likely because the topics covered were within their fields of interest.

2b. A workshop covering other technical areas received a generally positive response.

3. The topics of greatest interest for a future workshop were optical and electrical properties.

4. The greatest concensus was for workshops to be held annually.

5. There was significant willingness to participate on one manner or other in standards activities. Many companies expressed a willingness to supply specimens.

6. Standards related to thermal properties appeared to be the most needed. This result may have been influenced by the program of the meeting which, by emphasizing thermal properties measurements, attracted participants interested in that topical area. Some interest was also indicated for Raman and mechanical properties standards.

7. Several respondents agreed that these workshops should be conducted under the umbrella of a standards organization. Others responses were noncommital or negative. 


\section{Workshop on Characterizing Diamond Films}

\section{EVALUATION FORM}

Please return to: Albert Feldman

National Institute of Standards and Technology

A329 Materials Building

Gaithersburg MD 20899

Name

Organization

1. Was this workshop useful to your company?

Very Useful $\quad$ Neutral $\quad$ Not Useful

2a. Would you like to have another workshop covering the same topics?

\begin{tabular}{|c|c|}
\hline Very Useful & Neutral \\
\hline
\end{tabular}

2b. Other topics

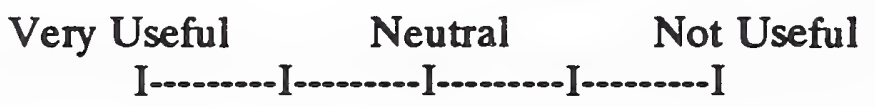

3. What topics?

Optical properties

Electrical Properties

Other

4. How often? Semiannually

Yearly

Other

5. Are you willing and able to participate in standards activities?

Can you provide specimens?

Can you make measurements as part of a round robin?

Can you take a leadership position in organizing standards activities?

(continued) 
6. What standards are needed?

Thermal

Raman

Other

What type of specimens are needed?

Dimensions

Thicknesses

Free

On a substrate

7. Do you want this activity under the umbrella of a standards org. (ASTM)?

8. Areas of interest in measurement.

Thermal

Mechanical

Optical

Electrical

Other (list)

Characterization

Raman

other

9. Suggested names of other participants:

10. Comments 


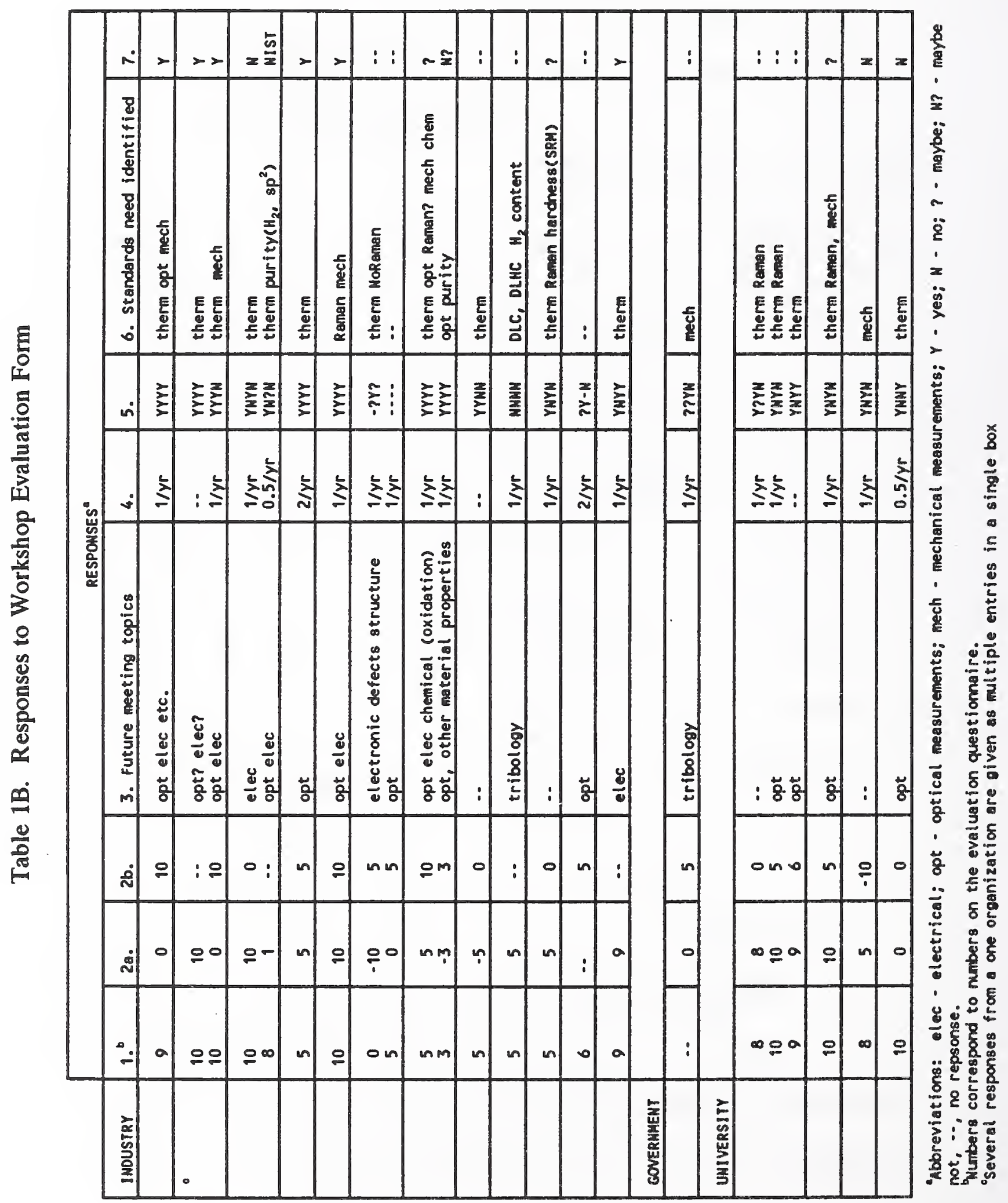


Appendix C. Workshop Program

\section{WORKSHOP on CHARACTERIZING DIAMOND FILMS \\ National Institute of Standards and Technology \\ Gaithersburg, MD 20899 \\ February 27, 28, 1992}

\section{PROGRAM}

Thursday Morning, February 27

Administration Building, Lecture Room D

\section{8:30am Refreshments}

9:00am Welcome - Lyle H. Schwartz, Director

Materials Science and Engineering Laboratory

9:15am Thermal Properties Measurement - Chairman, Charles Beetz, ATM

Several New Approaches to Thermal Measurements in CVD Diamond John Graebner

AT\&T Bell Laboratories

High Temperature Thermal Conductivity Measurements of Diamond using the Flash Diffusivity Technique

Jan Vandersande

Diamond Thermal Conductivity using the 3-Omega Technique David Cahill

J.R. Olson

Thermal Properties Evaluation of Diamond Films Ronald Tye
Jet Propulsion Laboratory

University of Illinois Cornell University

Sinku-Riko

10:45am Refreshments

11:00am Thermal Properties Measurement (Continued)

Studying Defects in Diamond Films using Thermal Conductivity Donald Morelli

General Motors

Thermal Property Characterization of CVD Diamond using Thermal Wave Techniques P.K. Kuo

Wayne State University

Measurement of Thermal Diffusivity by Converging Thermal Waves and Comparison with other

Measurement Techniques Grant Lu

Norton

Measuring Thermal Diffusivity by means of Photothermal Radiometry Albert Feldman and H.P.R. Frederikse

Discussion

12:30pm Lunch 
Thursday Afternoon, February 27

Administration Building, Lecture Room D

1:30pm Mechanical Properties Measurement - Chairman, Michael Drory, Crystallume

Fracture Surface Analysis of CVD Diamond

L.P. Hehn and J.J. Mecholsky

Preliminary Measurements of Strength and Fracture Toughness in CVD Diamond

Paul Klocek, J. Hoggins, T. McKenna, and J. Trombetta

J. Mecholsky

Fracture Toughness Measurement by Indentation Methods

Michael Drory

Texas Instruments

University of Florida

A Review of some Ultralow-Load Indentation Properties of Thermal-Filament CVD

Crystallume

Diamond Films

C.V. Cooper

Charles P. Beetz

United Technologies

ATM

3:00pm Refreshments

3:15pm Mechanical Properties Measurement (Continued)

Indentation Testing of Diamond Films

C.J. McHargue

Elastic Properties of Monocrystalline and Polycrystalline Diamond Claude A. Klein

University of Tennessee

Adhesion Testing of Diamond on Cemented Carbide Michael Drory

Raytheon

Crystallume

Discussion

5:00pm End of Session

(continued) 
Friday Morning, February 28

Administration Building, Lecture Room D

8:30am Refreshments

8:45am The Need for Standards - Chairman, Sandor Holly, Rockwell International

COMPANY PRESENTATIONS

J.W. Mitchell

Michael Drory

Kevin Gray

Sandor Holly

Paul Klocek

Clifford J. Robinson
AT\&T Bell Laboratories

Crystallume Norton Company Rockwell International

Texas Instruments

Raytheon

A Proposed Diamond Standard Reference Material

Edgar Etz

NIST

Discussion

10:45am Refreshments

11:00am NIST facilities

MicroRaman Spectroscopy

Edgar Etz

NIST

Cold Neutron Source: Detection of Hydrogen and Boron

George Lamaze

NIST

High Resolution X-ray Topography at the NSLS

David Black

NIST

Evaluation of CVD Diamond by Cathodoluminescence Imaging and Spectroscopy in a Scanning

Electron Microscope

L.H. Robins

NIST

12:00am The NIST Advanced Technology Program

John Gudas

NIST

12:30am Lunch

1:30pm Site visits

Diamond Deposition

Building 223/Materials Room B333

Cathodoluminescence

Building 223/Materials Room A210

MicroRaman Laboratory

Building 222/Chemistry Room A118

Cold Neutron Source

Building 235/Reactor

3:00pm Adjourn 
Appendix D.

\section{Abstracts}



Thermal Properties Measurement

Chairman, Charles Beetz, ATM 

Abstract for Talk at NIST Workshop on

Characterizing Diamond Films, February 27-28, 1992

\title{
Several New Approaches to Thermal Measurements in CVD Diamond
}

\author{
John E. Graebner, AT\&T Bell Laboratories \\ Murray Hill, NJ 07974
}

We have recently developed three techniques for measuring the thermal conductivity $\kappa$ of CVD diamond. (1) A two-heater heated bar technique uses a second heater on a standard sample to measure directly any loss of heat by radiation and to correct for it if necessary. (2) A laser flash technique using a 10-nsec heating pulse and high speed (100 $\mathrm{MHz}$ ) infrared thermometry is capable of measuring the thermal-diffusion transit time through a diamond film only $20 \mu \mathrm{m}$ thick. The use of thermal gratings is also being explored. (3) Thin-film thermocouples and thin-film heaters have been deposited on a diamond-on-silicon film to establish a steady thermal gradient for measuring $\mathrm{K}$. Using method (1) over a wide temperature range $(4-400 \mathrm{~K})$, we find in the best films that intrinsic (umklapp) phonon scattering dominates the conductivity above $-200 \mathrm{~K}$. Using both (1) and (2) on a series of carefully prepared films of varying thickness, we find a large (factor of 4) through-the-thickness gradient in both the perpendicular and parallel components of $\kappa$. Near the top surface of a $300 \mu \mathrm{m}$ film, the local $\kappa \approx 22 \mathrm{~W} / \mathrm{cmK}$, i.e., at least as good as the best single crystal diamond. 


\title{
HIGH TEMPERATURE THERMAL CONDUCTIVITY MEASUREMENT OF DIAMOND USING THE FLASH DIFFUSIVITY TECHNIQUE
}

\author{
Jan W. Vandersande
}

Jet Propulsion Laboratory/California Institute of Technology

Pasadena, CA 91109

The thermal conductivity of natural diamond has been measured between $300^{\circ} \mathrm{C}$ and $1000^{\circ} \mathrm{C}$ by means of the flash diffusivity method. This is the first time that the thermal conductivity of diamond has been measured above $400^{\circ} \mathrm{C}$. The experimental technique will be described in detail, such as setup, sample holder, sample coatings, data analysis, correction factors, etc. These results will present an upper bound for the thermal conductivity of diamond films. Expanding this technique to measure thin diamond films will also be discussed.

The electrical resistivity of natural type IIa diamond at room temperature is believed to be $10^{16} \Omega$-cm. It will be shown that this is not the actual value but an "apparatus limited" value and that the real resistivity is considerably higher. Measurements from room temperature to $1200^{\circ} \mathrm{C}$ on natural diamond and diamond films will also be presented. 


\title{
Diamond thermal conductivity using the 3-omega method
}

\author{
David G. Cahill, Department of Materials Science and Engineering, University \\ of Illinois, Urbana, IL 61801
}

J. R. Olson, Laboratory of Atomic and Solid State Physics, Cornell University, Ithaca, NY 14853

The 3-omega method ${ }^{1}$ is an AC technique for the measurement of thermal conductivity of bulk and thin film materials. A single, narrow metal line is deposited onto the surface of the sample and this line serves simultaneously as a heater and a thermometer in the experiment. The name 3-omega derives from the detection scheme -- the self heating of the metal line is measured by detecting a voltage oscillation at the third harmonic of the drive frequency. We have applied this technique to the study of a free-standing CVD diamond film and bulk crystals of natural diamond and isotopically pure diamond prepared at GE. The 3-omega method offers certain advantages in the characterization of CVD diamond films: the film does not need to be free-standing; the technique measures an average of the conductivity in the plane of the film and the perpendicular direction; and unlike most thermal wave techniques, the 3-omega method directly measures the thermal conductivity (not the thermal diffusivity).

${ }^{1}$ David G. Cahill, "Thermal conductivity measurement from 30 to $750 \mathrm{~K}$ : the 3-omega method," Rev. Sci. Instrum. 61, 802-808 (1990). 


\title{
Thermal Properties Evaluation of Diamond Films
}

b y

\author{
Ronald P. Tye \\ Sinku-Riko, Inc. \\ Kennebunk, ME
}

\section{ABSTRACT}

Considerable research and development has been undertaken in recent years on the development of diamond films for various applications where a very high thermal conductivity is required. Small size and form limitations on such.materials present a number of challenges to those desiring to evaluate thermal performance characteristics. As a result, there has been a need to develop new transient techniques specifically for measurements on very thin specimens.

One such technique is based on modified ac calorimetry. This undertakes direct measurement of the thermal diffusivity and heat capacity of thin films $(<0.3 \mathrm{~mm})$ of materials and layered composites. The basic technique will be described, together with several examples of its applications to characterize and evaluate the thermophysical properties of different diamond films deposited on substrates. The illustrations will include the dependence of thermal diffusivity on fabrication parameters and crystal size. 
Donald T. Morelli

Physics Department

General Motors Research Laboratories

The presence of defects at very low levels degrades the thermal conductivity of diamond films in a dramatic yet unclear fashion. We show that a classic steady state measurement of the thermal conductivity is a type of "phonon spectroscopy" capable of elucidating the nature of these defects and how they influence the thermal conductivity. Other advantages, as well as limitations, of the steady state technique will be discussed. 


\title{
THERMAL PROPERTY CHARACTERIZATION OF CVD DIAMOND USING THERMAL WAVE TECHNIQUES
}

\author{
P.K. Kuo \\ Department of Physics and Astronomy \\ Wayne State University \\ Detroit, MI 48201
}

The thermal wave-mirage effect method for the thermal property determination of CVD diamond is reviewed. This method requires a minimum of $2 \times 2 \mathrm{~mm}$ area of flat, metallized surface of CVD diamond, on a substrate or free standing. The thinnest free standing diamond measured by this method is about $5 \mu \mathrm{m}$. The highest diffusivity measured is 9.2 $\mathrm{cm}^{2} / \mathrm{s}$, which corresponds to a thermal conductivity of $16.7 \mathrm{~W} / \mathrm{cm} / \mathrm{K}$. 


\title{
MEASUREMENT OF THERMAL DIFFUSIVITY BY CONVERGING THERMAL WAVES AND COMPARISON WITH OTHER MEASUREMENT TECHNIQUES
}

\author{
Grant $\mathrm{Lu}$ \\ Norton Diamond Film \\ Goddard Rd. \\ Northboro, MA 01532
}

The converging thermal wave technique has been shown to provide an accurate and rapid measurement of thermal diffusivity without the need for any sample preparation. However, comparison of results with other measurement techniques highlights the difficulty in making accurate measurements. An initial round-robin test of the same sample at five different laboratories produced results from 1200 to $1670 \mathrm{~W} / \mathrm{m} / \mathrm{K}$. A second round of testing on another sample at three laboratories showed results from 1280 to $1770 \mathrm{~W} / \mathrm{m} / \mathrm{K}$.

Discrepancies are clearly beyond the stated level of error for each measurement. 


\title{
MEASURING THERMAL DIFFUSIVITY BY MEANS OF PHOTOTHERMAL RADIOMETRY
}

\author{
Albert Feldman and H.P.R. Frederikse* \\ Ceramics Division \\ Materials Science and Engineering Laboratory \\ National Institute of Standards and Technology** \\ Gaithersburg, MD 20899
}

Photothermal radiometry is being investigated as a technique for measuring thermal diffusivities of diamond films. As used at NIST, the method employs a modulated laser beam to heat the surface of the specimen. A portion of the specimen surface is imaged with a $\mathrm{CaF}_{2}$ lens onto an InSb detector; thus, the signal obtained is a measure of the modulated local surface temperature. The phase and magnitude of the surface temperature can be measured as a function of modulation frequency and as a function of detector position to obtain the thermal diffusivity. Two geometries are under study; a heated region with a cylindrically symmetric gaussian profile, corresponding to focusing the laser beam with a lens, and a heated region in the form of a circular ring, which is achieved by placement of an axicon lens in the laser beam. Extensive modeling of the thermal wave propation in these geometries has been done; the modeling takes into account any number of layers in the specimen. A particular problem associated with the method is the need for a uniform absorbant coating to maximize specimen heating and thermal emission. The gaussian beam geometry has been used to obtain the diffusivity of a CVD diamond plate $0.24 \mathrm{~mm}$ thick. The circular ring geometry is still being investigated.

\footnotetext{
* Consultant to NIST.

**Technology Administration, U.S. Department of Commerce
} 
Mechanical Properties Measurement Chairman, Michael Drory, Crystallume 



\title{
FRACTURE SURFACE ANALYSIS OF CVD DIAMOND
}

\author{
L.P. Hehn and J.J. Mecholsky, Jr. \\ Department of Materials Science and Engineering \\ University of Florida \\ Gainsville, FL 32611
}

There are many reasons to use diamond in coatings and bulk form as a structural material. However, because of expense and high hardness, it is sometimes difficult to evaluate the structural response of diamond materials made through different processes. For example, one property that is difficult to measure is the fracture toughness of the material.

The fracture toughness or resistance to rapid crack growth can be measured by the critical stress intensity factor, $\mathrm{K}_{\mathrm{IC}}$, and critical fracture energy, $\gamma_{\mathrm{c}} . \mathrm{K}_{\mathrm{IC}}$ is measured in units of stress-distance ${ }^{1 / 2}$, e.g., $\mathrm{MPa} \cdot \mathrm{m}^{1 / 2}$ and $\gamma_{\mathrm{c}}$ is measured in units of energy/unit area, e.g., $\mathrm{J} / \mathrm{m}^{2}$. [In plane stress, $\mathrm{K}_{\mathrm{IC}}=\left(2 \mathrm{E} \gamma_{\mathrm{c}}\right)^{1 / 2}$, where $\mathrm{E}$ is the elastic modulus.] Fracture mechanics specimens are used to evaluate these quantities. However, typically, the cracks in these specimens are of the order of $\mathrm{mm}$ in size. Thus, the specimens have to be relatively large. In the case of diamond, large specimens can be expensive and the measurements technically challenging. It would be useful to be able to evaluate the resistance to fracture from a strength specimen, since the strength values are of interest because of design considerations.

Fracture surface analysis is used to examine the fracture surface of strength specimens to obtain the size of the fracture initiation crack, $c$, and details of the surrounding topography. From these measurements, and, with the knowledge of the stress at failure, $\sigma$, the fracture toughness, $\mathrm{K}_{\mathrm{IC}}$, can be calculated, $\mathrm{K}_{1 \mathrm{C}}=\mathrm{Y} \sigma \mathrm{c}^{1 / 2}$, where $\mathrm{Y}$ is a constant based on the loading and crack geometry. For a small surface crack in a relatively large specimen, $\mathrm{Y}=1.24$.

This presentation demonstrates the techniques of fracture surface analysis as applied to diamond disks ${ }^{*}$ and diamond coatings ${ }^{* *}$ on silicon single crystals. The value $\mathrm{K}_{\mathrm{IC}}$ found for CVD diamond disks averaged approximately $6 \mathrm{MPa} \cdot \mathrm{m}^{1 / 2}$. This value is in agreement with the value of approximately $7 \mathrm{MPa} \cdot \mathrm{m}^{1 / 2}$ found in this study and with the values between 3.5 and $7.4 \mathrm{MPa} \cdot \mathrm{m}^{1 / 2}$ found by Drory et al. ${ }^{* * *}$ on other CVD diamond films; both studies used a crack indentation technique. The role of crack size to grain size ratio will be discussed in terms of the resistance to crack growth. The advantages and disadvantages of the various techniques will be contrasted and compared. Proper measurements for design considerations should involve both large and small crack techniques.

\footnotetext{
* Texas Instruments, Inc.,

** Penn State University

*** Drory, Gardinier and Speck, J. Am. Cer. Soc. 74 [12] 3148-50 (1991).
} 


\title{
PRELIMINARY MEASUREMENTS OF STRENGTH AND FRACTURE TOUGHNESS OF CVD DIAMOND
}

\author{
P. Klocek, J. Hoggins, T. McKenna and J. Trombetta \\ Texas Instruments \\ P.O. Box 655012 MS 55 \\ Dallas, TX 75265
}

\author{
AND \\ J. Mecholsky \\ University of Florida \\ Materials Science and Engineering Dept. \\ 256A Rhines Hall \\ Gainesville, FL 32611
}

With the rapid development of CVD diamond and the interest in inserting this technology into applications, there is an increasing requirement for physical property data. This is particularly true in the area of mechanical properties where little characterization has been reported. This paper represents a preliminary study of the strength and fracture toughness in thick free-standing CVD diamond synthesized by a dc arc discharge plasma torch. CVD diamond samples were cut into discs ranging in diameter from 0.3 to 0.6 inches and thickness from $40 \mathrm{um}$ to over $800 \mathrm{um}$. A ball and ring flexure strength apparatus was used to measure the strength of both polished and unpolished discs. Strength values were as high as $385 \mathrm{kpsi}$ and averaged over $100 \mathrm{kpsi}$. The fracture toughness as determined by fractography is 7 to $8 \mathrm{MPa} \mathrm{m}{ }^{1 / 2}$. The strength and fracture toughness data will be presented along with optical, $\mathrm{x}$-ray diffraction and morphological properties of the test samples. 


\title{
FRACTURE TOUGHNESS MEASUREMENT BY INDENTATION METHODS
}

\author{
M. D. Drory \\ Crystallume \\ 125 Constitution Drive \\ Menlo Park, CA 94025
}

\begin{abstract}
$\underline{\text { Abstract }}$
The fracture toughness of CVD diamond is estimated by a Vickers indentation method. Free-standing diamond films of $400 \mu \mathrm{m}$ thickness are produced with plasma-enhanced chemical vapor deposition and highly polished for indentation testing. Indentation testing was performed with a microhardness tester using a load range of 5 to $8 \mathrm{~N}$. The average fracture toughness is estimated as $5.3 \pm 1.3 \mathrm{MPa} \sqrt{\mathrm{m}}$.
\end{abstract}




\section{A REVIEW OF SOME ULTRALOW-LOAD INDENTATION PROPERTIES OF THERMAL-FILAMENT CVD (TFCVD) DIAMOND FILMS}

C. V. Cooper, United Technologies Research Center, East Hartford, CT 06108 C. P. Beetz, Jr., Advanced Technology Materials, Danbury, CT 06810

A brief review of the deposition and ultralow-load indentation properties of thermal-filament CVD diamond films will be presented and discussed. The work to be reviewed includes (1) the effects of methane concentracion in hydrogen on the resulting hardness, (2) an investigation of the anisotropy in hardness and elastic modulus homoepitaxial films on type IIa substrates of three crystallographic orientations, and (3) the effects of boron and phosphorus doping on the resulting hardness of homoepitaxially deposited CVD diamond.

Because of its simplicity of design and operation and the expected relative ease of scaleup to production requirements, a reactor of the thermal-filament type was chosen as the technique for the synthesis of diamond films for these studies. In all cases, deposition from the vapor phase was accomplished from pure sources of methane and hydrogen without the assistance of oxygen or halogen gases at chamber pressures of approximately 10 torr and total gas flow rates of 100 standard $\mathrm{cm}^{3} \mathrm{~min}^{-1}$. With the exception of boron and phosphorus, which were introduced by design for the doping studies, the only impurities of significance which were detected by SIMS in the deposited films were hydrogen from the source gas $\left(\approx 10^{18} \mathrm{~cm}^{-3}\right)$, silicon from the substrate $\left(\approx 10^{17} \mathrm{~cm}^{-3}\right)$, and tungsten from the thermal filament $\left(\simeq 10^{17} \mathrm{~cm}^{-3}\right)$.

The major conclusions from indentation studies were as follows: (1) surface roughness of as-deposited films led to unacceptable scatter in the measurements and apparent hardnesses greater than actual, (2) TFCVD diamond films exhibited a monotonic increase in hardness with decreasing methane concentration over the range of methane concentrations from 0.15 vol \% to 1.00 vol $\%$, (3) the scatter in the measurement precluded meaningful determination of any anisotropy in the hardness or elastic modulus of homoepitaxial diamond films on $\{100\},\{110\}$, and $\{111\}$ faces of type IIa substrates, and (4) while both boron- and phosphorus-doped synthetic films were softer than the type IIa monolith, phosphorus was the more effective hardening dopant. 


\section{INDENTATION TESTING OF DAMMOND FIMS \\ Carl J. McHargue}

\section{Department of Materials Science and Engineering University of Tennessee-Knozville}

\section{Abstract}

A discussion of factors influencing indentation measurements of thin films and hard materials will be given. A load-depth sensing microindentation instrument (the Nanoindenter ) will be described. Hardness values ranging from 5 to $15 \mathrm{GPa}$ and elastic (Young) modulus values of 40 to $130 \mathrm{GPa}$ have been measured for DLC films deposited by a variety of techniques. Hardness and modulus values for CVD diamond films from two sources are similar to those measured on the (100) plane of natural type II a diamond. 


\title{
ELASTIC PROPERTIES OF MONOCRYSTALLINE AND POLYCRYSTALLINE DIAMOND
}

\author{
Claude A. Klein \\ Raytheon Company. Research Division \\ 131 Spring Street. Lexington. M.A 0217.3 \\ 617-860-3113 (FAX:-3195)
}

Any evaluation of diamond as an engineering material requires proper values for Young's modulus and Poisson's ratio. The modulus of single-crystal diamond is often set equal to $1 / S_{11}$, or $E=1050 \mathrm{GPa}$, which assumes that it does not vary greatly with orientation $^{1}$ : regarding Poisson's ratio. most data compilations list $\nu=0.2$ as an appropriate "average" value. In fact. since the elastic constants of diamond are know with great accuracy. $^{2}$ it is a straightforward matter to derive exact numbers for both $E$ and $\nu$ that take into consideration the intrinsic anisotropy as well as the crystalline configuration. For highly textured (110) polycrystalline CVD deposits, the appropriate values are $E=1150$ $\mathrm{GPa}$ and $\nu=0.0770$, based on a simple averaging procedure. For randomly orientated aggregates. the Hashin-Shtrikman bounds vield almost identical results. $E=1140 \mathrm{GPa}$ and $\nu=0.0694$. which are quite consistent with values derived for the high-symmetry planes. Recent measurements of the biaxial modulus. ${ }^{3} \mathrm{M}=\mathrm{E} /(1-\mathrm{v})$. of CVD-diamond films point to $\mathrm{M}=1198 \pm 43 \mathrm{GPa}$. which demonstrates that state-of-the-art deposits exhibit elastic properties compatible with the compliances of natural single-crystal diamond.

1 J. Field, ed.. The Properties of Diamond (Academic Press, London/UK. 1979. Appendix.

2 H. McSkimin. P. Andreatch. and P. Glynn. J. Appl. Phys. 43. 985 (1972).

3 G. Cardinale, Private Communication (Raytheon Research Division, Lexington/MA. 18 jul 911. 


\title{
ADHESION TESTING OF DIAMOND ON \\ CEMENTED CARBIDE
}

\author{
M. D. Drory \\ Crystallume \\ 125 Constitution Drive \\ Menlo Park, CA 94025
}

\begin{abstract}
$\underline{\text { Abstract }}$
Successful development of diamond coated tooling requires a quantitative measurement of adhesion between diamond and cemented carbide. The brale indentation method is explored whereby a circular interface crack is created under applied load. A model is presented which focuses on the plastic deformation near the indenter that results in mode I loading of the film. In particular, an Obreimoff-type analysis is used to relate interface toughness to the plastic deformation near the indenter, film thickness, Young's modulus, and applied load.
\end{abstract}



The Need for Standards

Chairman, Sandor Holly, Rockwell International 

Quality Assurance of Characterizations of CVD Diamond Films

\author{
J. W. Mitchell \\ Bell Laboratories \\ 600 Mountain Avenue \\ Murray Hill, New Jersey 079743
}

\begin{abstract}
CVD diamond is an extreme example of a material with physical and chemical properties depending strongiy upon conditions ana mernods of growth. Consequenriy, only through detailed characterizations of deposited films and by definitive correlations of measured properties with growth conditions, can films with specified properties be either grown reproductively or selected from various sources of supply. On the front end, establishing satisfactory specifications for physical and chemical properties of diamond depend on the application for which the material is intended. Then, following the definition of a practical set of specifications, direct measurements are made to confirm that the material meets compliance for specified properties. Such qualifications of CVD diamond require reliable methods for measuring selected properties, and also necessitates that an appropriate protocol be developed for completely characterizing the materials.

We describe a generally applicable analytical protocol for the evaluation of CVD diamond. Using the established sequence of complimentary techniques, films meeting specified properties have been selected reliably from various sources. Several other unmet challenges in measurements of diamond materials for electronic applications are discussed. These include high resolution thermal conductivity, quantitative assessments of $\mathrm{sp}^{3}$ to $\mathrm{sp}^{2}$ carbon content of DLC, resistivity characterizations, and determination of the adhesion strength of metallizations to diamond. Quality assurance of these characterizations depend critically on comparison standards and reference measurement techniques, which need to be developed.
\end{abstract}


NEEDS FOR FURTHER TEST DEVELOPMENT AND

STANDARDS IN CVD DIAMOND TECHNOLOGY

M. D. Drory

Crystallume

125 Constitution Drive

Menlo Park, CA 94025

\begin{abstract}
$\underline{\text { Abstract }}$
Several aspects of CVD diamond characterization are in need of further test develop and eventual standardization. These include thermal properties measurements and determination of mechanical strength. This is important for several applications at Crystallume. For example, thick-section diamond composites have been developed for use in thermal management applications, but present additional challenges for thermal properties measurements. The needs for standard strength measurements will also be discussed for free-standing films. Current use of the burst test for estimating the strength of CVD diamond films requires additional considerations, such as initial film curvature and size effects.
\end{abstract}




\title{
STANDARDIZED DIAMOND FILM CHARACTERIZATION \\ FOR THE COMMERCIAL MARKET
}

\author{
Kevin Gray \\ Norton Diamond Films \\ Goddard Rd. \\ Northboro, MA 01532
}

To many technical and management personnel responsible for the manufacture of a product, CVD diamond has remained a laboratory curiosity. The sentiment is often expressed that the insertion of CVD diamond into product lines remains for the future. Recent developments have demonstrated, however, that high quality diamond films are commercially available, allowing the unique properties of diamond to be exploited to meet todays' technological requirements. It is precisely the uniqueness of diamond properties that result in the difficulty of CVD diamond characterization. Given the specialized techniques employed to measure diamond properties, it is likely that these techniques will be unfamiliar to may product engineers. And, with the variety of techniques used to measure any specific property, the CVD diamond industry would benefit from a cooperative effort to establish standardized measurement techniques and materials. Enhanced consumer confidence would result and the viability of CVD diamond in today's market would be reiterated. 


\title{
THE NEED FOR STANDARDS IN INDUSTRY
}

\author{
Sandor Holly \\ Rocketdyne Division \\ Rockwell International Corporation \\ 6633 Canoga Avenue \\ Canoga Park, CA 91303
}

Most tasks in Rockwell's aerospace activities depend heavily on capabilities of the materials that are used. The design phases depend on material characteristics that are usually available in tabulated and graphical forms. The depth of data base for CVD diamond is still very limited. More significantly, much of the data that may be available have been collected under somewhat obscure (or undefined) conditions. There is no general agreement on the relative importance of process parameters, the methods used in monitoring these parameters and the conditions under with these parameters are measured.

Proposed diamond applications span a huge range of technical fields, each with its specialized sets of needs, methods and vocabulary. Researchers with widely varying backgrounds need to communicate with one another. Without established standards of characterizing CVD diamond, these communications are unnecessarily complex, confusing and likely to break down.

Rocketdyne Division of Rockwell International Corp., is actively pursuing diamond film applications in mechanical, thermal and optical areas. Some examples of applications, showing the need for accepted standards in this area will be discussed. 


\title{
ISSUES AND NEEDS FOR STANDARDIZATION OF CVD DIAMOND CHARACTERIZATION AND TESTING
}

\author{
P. Klocek \\ Texas Instruments \\ P.O. Box 655012 MS 55 \\ Dallas, TX 75265
}

Due to the current limitation of CVD diamond technology, it is often difficult to prepare adequate specimens in terms of size, geometric tolerances and quantities for standardized or accepted test methods. This creates at least a temporary need for standardized testing and test specimen standards to adequately assess the status of CVD technology and its operational performance in a potential application. The issues of standardized characterization and testing of CVD diamond will be discussed in the context of both required fundamental structure or defect/property relation understanding and specific applications. Optical, mechanical and thermal applications will be emphasized with a discussion of the needs for test sample standards and standardized tests and data analysis techniques. 


\title{
CVD DIAMOND \\ CURRENT STATUS AND REOUIREMENT FOR STANDARDS
}

\author{
Clifford J Robinson \\ Raytheon Company, Research Division \\ Lexington, MA 02173
}

CVD diamond technology has advanced significantly over the past twelve months to the extent that free standing polycrystalline diamond can now be produced in large area with high optical transmission in the visible spectrum. With increased chemical purity and decreased lattice defects, the quality of the CVD diamond approaches and possibly surpasses that of natural type Ila diamond. Characterization of the material becomes a more challenging task as hydrogen content is reduced to below $100 \mathrm{ppm}$ and $\mathrm{sp}^{2}$ bonded carbon content is reduced to below the detection limit normally attainable by Raman Spectroscopy. Results of thermal conductivity measurements, FTIR spectroscopy, NMR spectroscopy and microwave dielectric loss are presented in the overall framework of characterizing defects in the material. Of all the techniques available, FTIR is the most sensitive to lattice defects and single phonon absorption appears the most useful for determining material quality. The technique is not quantitative however and the need for standards exists for quantitative measurement of absorption in the single phonon region of the IR spectrum of diamond. 


\title{
A PROPOSED DIAMOND STANDARD REFERENCE MATERIAL
}

\author{
Edgar Etz and Albert Feldman
}

NIST

The new diamond technology is bringing on the commercialization of products and devices largely based on various chemical vapor deposition (CVD) methods that produce synthetic diamond as bulk material, hard coatings, and thin films. Quality control measures used by industry are now beginning to define the need for calibration standards and standard measurement methods for characterizing the key properties of diamond. This workshop, in part, aims to focus on this need for standards, and their development, in critical areas of this emerging technology. We propose here the development of a standard for the chemical characterization of CVD diamond by Raman spectroscopy. This proposal is based on the recognition that Raman spectroscopy has evolved as the benchmark analytical technique for the overall characterization of CVD diamond and diamond-like carbon. An extensive Raman literature now exists that correlates the Raman spectrum of CVD diamond with several of its key conditions, growth, morphology, structure, and composition. We will present our rationale for proposing a polycrystalline thin diamond film, on silicon wafer substrate, as a suitable reference material for the chemical and structural characterization of CVD diamond. We will discuss the desired properties of such a standard, how it may be fabricated, and what the measurement protocol should be to evaluate its reference properties. In the experimental design, the use of the Raman microprobe is suggested to ascertain homogeneity of composition at the microscopic level as one of the principal criteria for industrial CVD diamond of high quality. With input from the diamond industry and research community, we hope to make the diamond reference standard as broadly applicable as possible. 

NIST Facilities 



\title{
MICRO-RAMAN SPECTROSCOPY OF DIAMOND AND DLC FILMS
}

\author{
Edgar S. Etz \\ Microanalysis Science Group \\ Surface and Microanalysis Science Division / CSTL \\ National Institute of Standards and Technology ${ }^{*}$ \\ Gaithersburg, MD 20899
}

Several Raman systems are in use at NIST for the characterization of a broad range of materials. In general, normal (i.e., non-resonance enhanced) Raman scattering is excited employing any one of the common laser wavelengths from the blue to the red region of the spectrum. The types of Raman instruments employed in our laboratories comprise conventional scanning monochromators with cooled photomultiplier detection and Raman (triple) spectrographs with various optical multichannel detection systems. These instruments can be employed in either the macro-, or bulk, sampling mode, or in the micro-sampling mode where they perform as true microprobe instruments furnishing a lateral spatial resolution approaching 1 micrometer. Our studies of CVD diamond and DLC films are routinely carried out by both macro- and micro-Raman measurements using either $488.0 \mathrm{~nm}$ or $514.5 \mathrm{~nm}$ excitation from an argon ion laser. With the Raman microprobe, utilizing a standard microscope in the fore-optical system, spectra can also be excited with the $647.1 \mathrm{~nm}$ line of a krypton ion laser. This is advantageous for highly luminescing samples. The present microprobe utilizes an intensified diode array as the detector. Spectra of CVD diamond films are readily observed in integration times of a few seconds at laser irradiances of typically 10-40 mW (at the sample). Spectra are usually acquired with a spectral resolution of 3-6 $\mathrm{cm}^{-1}$ depending on the grating selected in the spectrograph stage. We have plans to automate the sample stage to permit the computerized scanning and mapping of the analytical specimen. This capability will permit a more comprehensive assessment of the spatial homogeneity of sample composition and structure.

*Technology Administration, U.S. Department of Commerce 
Cold Neutron Source: Detection of Hydrogen and Boron

G.P. Lamaze, R.M. Lindstrom, and R.G. Downing Nuclear Methods Group, NIST

The Nuclear Methods Group at NIST operates two instruments at the Cold Neutron Research Facility (CNRF): the cold Neutron Depth Profiling instrument (CNDP) and the cold Neutron Prompt Gamma instrument (CNPG). The neutron beams for these instruments originate from a 16 liter $\mathrm{D}_{2} \mathrm{O}$ ice cold source operated at about $40 \mathrm{~K}$. The neutron energy spectrum is best described by a $65 \mathrm{~K}$ Maxwellian. The CNPG beam is contained in a neutron guide that allows the beam to be taken through the walls of the reactor containment building into a neighboring building with little loss of neutrons. The CNDP instrument is at the immediate exit of the biological shield surrounding the reactor vessel.

The neutron depth profiling technique is particularly well suited for the detection of boron, lithium, and nitrogen in the near surface regions of solids. NDP analysis yields both concentration and depth distribution of the analyte. Results of recent measurements of boron in CVD diamonds will be presented.

The prompt gamma technique has become a very powerful tool for the non destructive analysis of hydrogen in bulk samples. The low background in the neutron guide hall permits measurements with sensitivities of better than $10 \mu \mathrm{g} / \mathrm{g}$. Applications of the analysis of hydrogen in CVD diamonds will be discussed. 


\section{$\mathrm{X}$-ray Diffraction Imaging of Diamond \\ David Black, Ceramics Division, NIST}

$\mathrm{X}$-ray diffraction topography is a very sensitive technique for imaging the defect microstructure of single crystals. Image contrast results from disruption of the diffraction condition by areas of misorientation, strain or other crystallographic defects such as dislocations, impurities or the presence of other phases. The diffracted image is recorded on high resolution media which provides a map of the defect microstructure of the sample.

The MSEL $\mathrm{x}$-ray beamline at the NSLS is a unique high resolution monochromatic diffraction imaging facility which is currently being used to study the defect microstructure of diamond single crystals and of homoepitaxial CVD diamond films. The uniqueness of this facility lies in the fact that it makes use of a nearly parallel and monochromatic $x$-ray beam of large cross section (up to $5 \times 5$ $\mathrm{cm}$ ) which is created using asymmetric optics. The energy resolution of $\sim 1-2 \mathrm{eV}$ and the beam divergence of $\sim 1$ arcsecond make this system one of the best in the world.

This system has been used to study natural type Ia and IIa substrates for CVD growth of homoepitaxial diamond and to characterize the resulting epitaxial film. Man made type IIa crystals have also been studied to better understand the relationship between growth conditions and microstructure. 


\title{
EVALUATION OF CVD DIAMOND BY CATHODOLUMINESCENCE IMAGING AND SPECTROSCOPY IN A SCANNING ELECTRON MICROSCOPE
}

\author{
Lawrence H. Robins \\ Ceramics Division \\ Materials Science and Engineering Laboratory \\ National Institute of Standards and Technology \\ Gaitherburg, MD 20899
}

Defect centers that possess electronic energy levels within the forbidden energy gap of an insulating material such as diamond can have a significant influence on the optical and electronic properties of the host material. Some types of defect centers have a high probability of giving rise to luminescence (the emission of a photon) following excitation out of the ground state. Luminescence spectroscopy is a sensitive probe of these centers. My research has centered on the characterization of defects in CVD diamond by cathodoluminescence (electron-beam-excited luminescence) imaging and spectroscopy in a scanning electron microscope (SEM). The main advantage of doing cathodoluminescence in the SEM is that the excited region of the specimen can be restricted to a volume of $\sim 1 \mu \mathrm{m}^{3}$. This allows the spatial variation in the luminescence spectrum to be mapped with high resolution, and thus provides information about the spatial distribution of luminescence centers. In this talk, after briefly discussing the design of the cathodoluminescence experiment, I will present some of the most interesting results obtained from this experiment. The luminescence spectra that we observe in CVD diamond are attributed to centers containing atomic vacancies, interstitials, dislocations, and nitrogen and silicon impurity atoms. Significant spatial variations in the luminescence have been observed within faceted single-crystal particles and also within polycrystalline films viewed in cross-section. Finally, I will discuss some of the factors that make it difficult to determine the absolute concentration of a luminescence center from the observed luminescence intensity.

"Technology Administration, U.S. Department of Commerce 
Appendix E.

\section{Company Presentation Materials}





\title{
Presented by
}

\author{
J. W. Mitchell
}

AT\&T Bell Laboratories

QUALITY ASSURANCE OF

C H A R A C T E RIZ A TIONS

OF C V D D IAMOND 
CHA R A C TERIZ A TION

CHEMISTS

$\begin{array}{ll}\text { J. Mucha } & \text { MWPCVD } \\ \text { L. Seibles } & \text { IR, RA, PL } \\ \text { J. Graebner } & \text { TC } \\ \text { M. Ellington } & \text { SEM } \\ \text { F. Biocchi } & \text { RBS } \\ \text { H. Luftman } & \text { SIM, AES } \\ \text { T. Purnell } & \text { DEKTAK } \\ \text { L. Heimbrook } & \text { LIMA } \\ \text { S. Nakahara } & \text { TEM }\end{array}$

D E S I R A B L E C V D

D I A M O N D S T A N D A R D S

A N D / O R STA NDARD METHODS

PURITY STANDARD ( $\mathrm{H}_{2}, \mathrm{SP}^{2}$ Content)

BULK TRANSVERSE

THERMAL CONDUCTIVITY

ADHESION MEASUREMENT METHOD

RESISTIVITY METHOD/MATERIAL 


\section{QUALITY ASSURANCE OF CVD DIAMOND FOR HEAT SINKS *}

\section{PURITY}

THERMAL CONDUCTIVITY

RESISTIVITY

THICKNESS \& UNIFORMITY

SURFACE TOPOGRAPHY

MORPHOLOGY

STRESS

* Materials also must meet processability requirements.

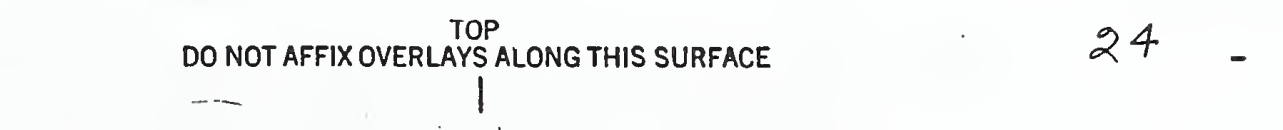

CHARACTERIZATION PROTOCOL

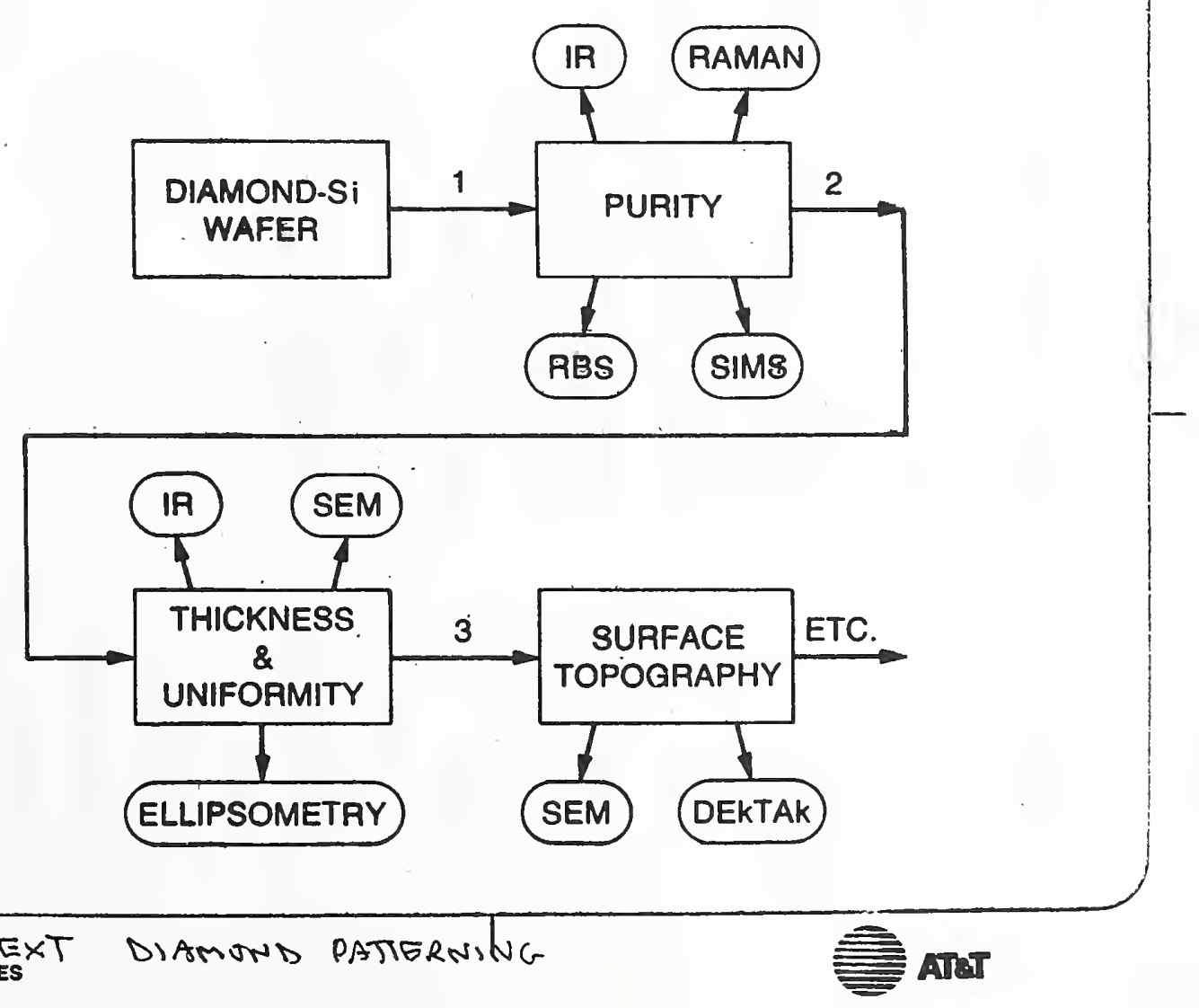




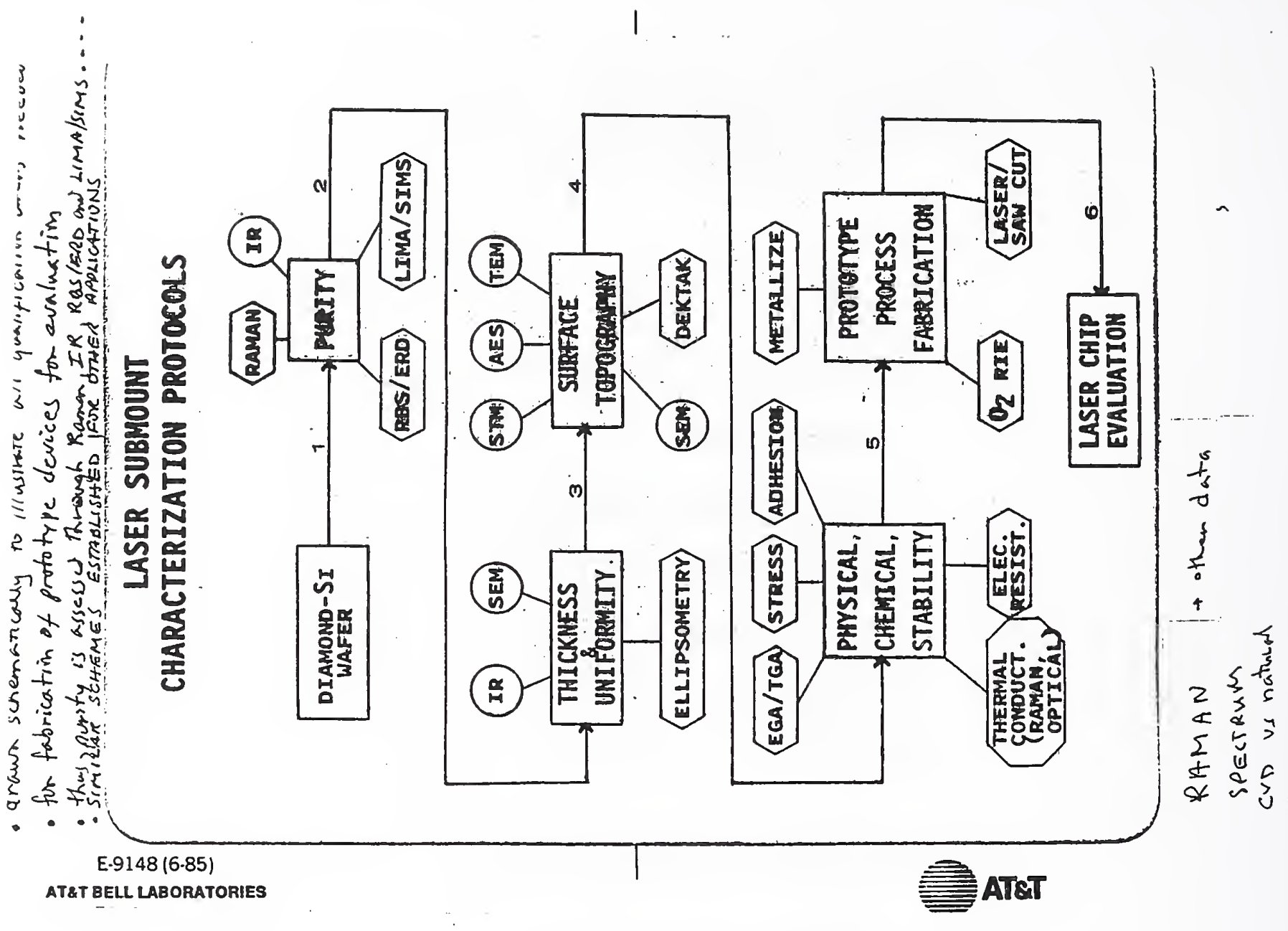

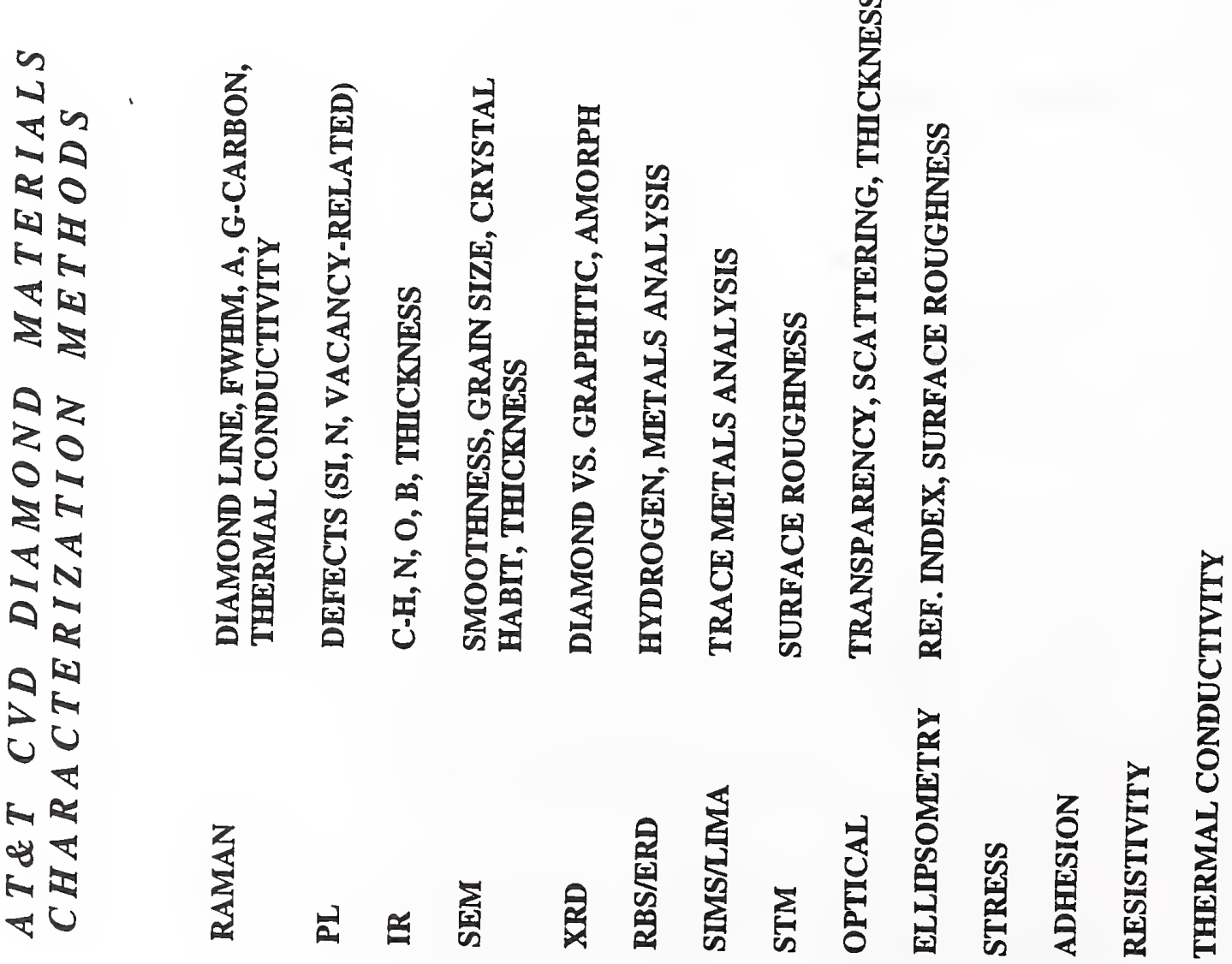


APPLICATIONS OF

INTEREST TO AT\&T

HEAT SINKS

ELECTRONIC DEVICES

OPTICS

X-RAY LITHOGRAPHY MASKS

PARAMETERS SPECIFIED FOR DIAMOND HEAT SINKS
Adhesion
Grain Size
Resistivity
Size
Stress
Deposition Rate
Purity (a, g-carbon; H-) Surface Roughness
Thermal Conductivity Thickness and Uniformity 


\section{FIRST LAW OF CVD \\ DIAMOND DEPOSITION}

DETAILED CHARACTERIZATIONS OF FLMS

AND DEFINITIVE CORRELATIONS OF

MEASURED PROPERTIES WITH GROWTH

CONDITIONS ARE REQUIRED TO REPRODUCIBLY

PRODUCE FILMS MEETING SPECIFIED PROPERTIES.

\section{GROWTH CONDITIONS IMPACT \\ PHYSICALAND CHEMICAL P R O P E R T I S}

$\begin{array}{ll}\text { Surface Smoothness } & \mathrm{SP}^{3} \text { to } \mathrm{SP}^{2} \\ \text { Thermal Conductivity } & \text { Grain Size } \\ \text { Morphology } & \text { Resistivity } \\ \text { Adhesion } & \text { Color } \\ \text { Optical Transparency } & \text { Hardness }\end{array}$




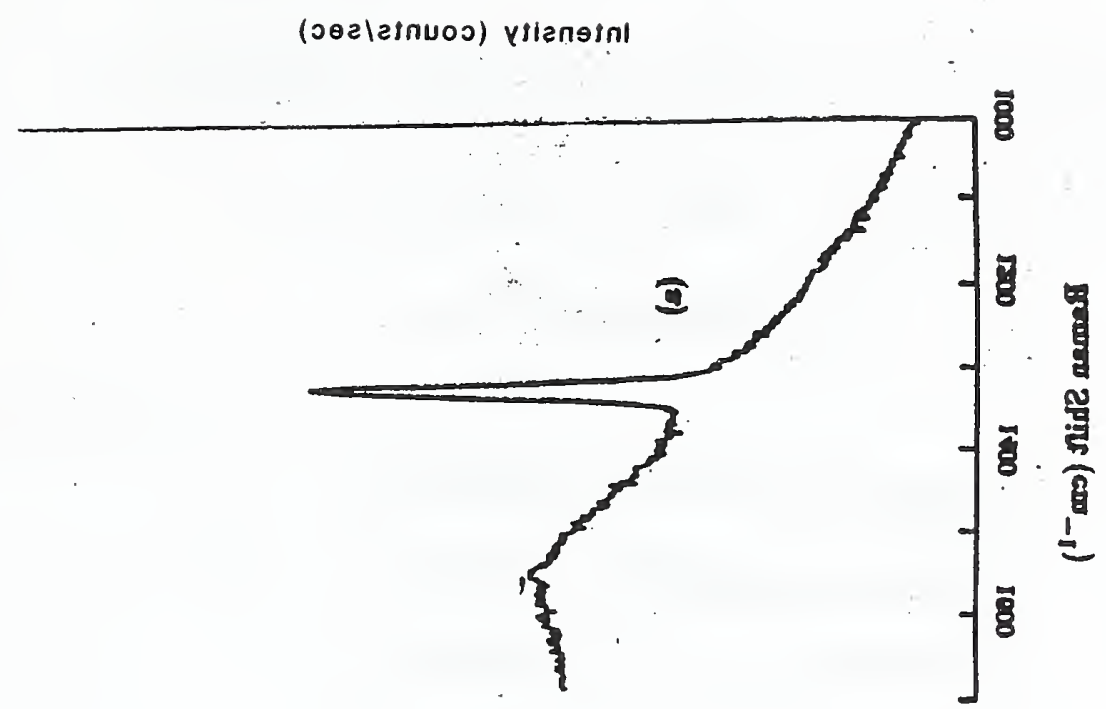

PROCESS VARIABLES AND GROWTH

PARAMETERS IN MW PLASMA

DEP OSITION OF CVD DIAMOND

Gas Phase Composition

Pressure

Substrate Temperature

Plasma Electric Field Strength

Deposition Rate And Duration 


\section{GROWTH CONDITIONS IMPACT PHYSICAL AND CHEMICAL PROPERTIES}

$\begin{array}{ll}\text { Surface Smoothness } & \mathbf{S P}^{3} \text { to SP} \\ \text { Thermal Conductivity } & \text { Grain Size } \\ \text { Morphology } & \text { Resiativity } \\ \text { Adhesion } & \text { Color } \\ \text { Optical Transparency } & \text { Hardness }\end{array}$

D I A M O N D S - C - P RELA T IONSH I PS

PROPERTY

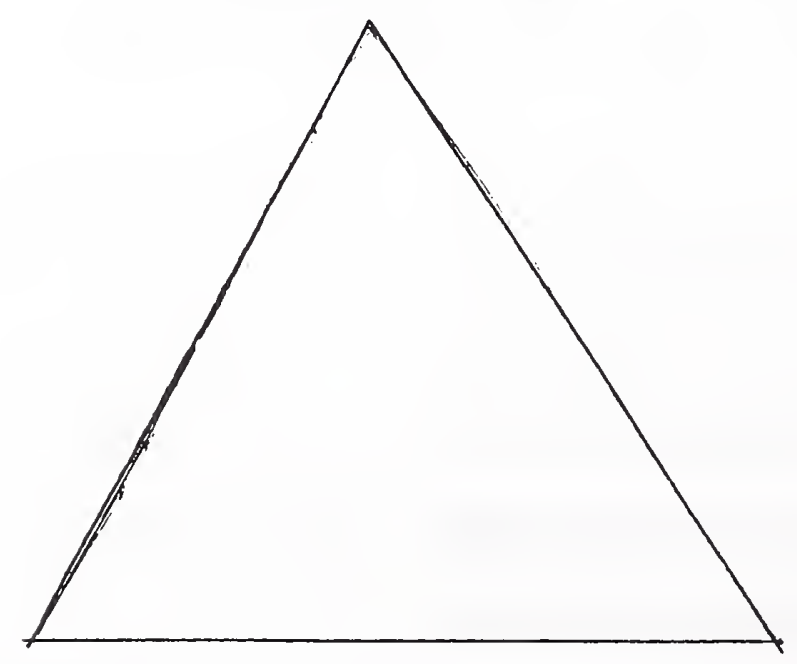




\section{PROCESS VARIABLES AND GROWT PARAMETERS IN MW PLASMA DEPOSITION OF CVD DIAMOND}

Gras Phase Composition

Pressure

Substrate Temperature

Plasma Electric Field Strength

Deposition Rate And Duration

Substrate Temp $925^{\circ}$

$\begin{array}{ll}\text { Pressure } & 70 \text { torr } \\ \text { Flow } & 300 \mathrm{SC} \\ 1.5 \mathrm{KV} & \text { Power } \\ 2450 \mathrm{MgH}_{2} & \text { Frequency } \\ \text { Growth time } & \text { 24 Hours }\end{array}$




\title{
CVD Diamond
}

\author{
Clifford J Robinson \\ Raytheon Company - Research Division
}

28th February 1992

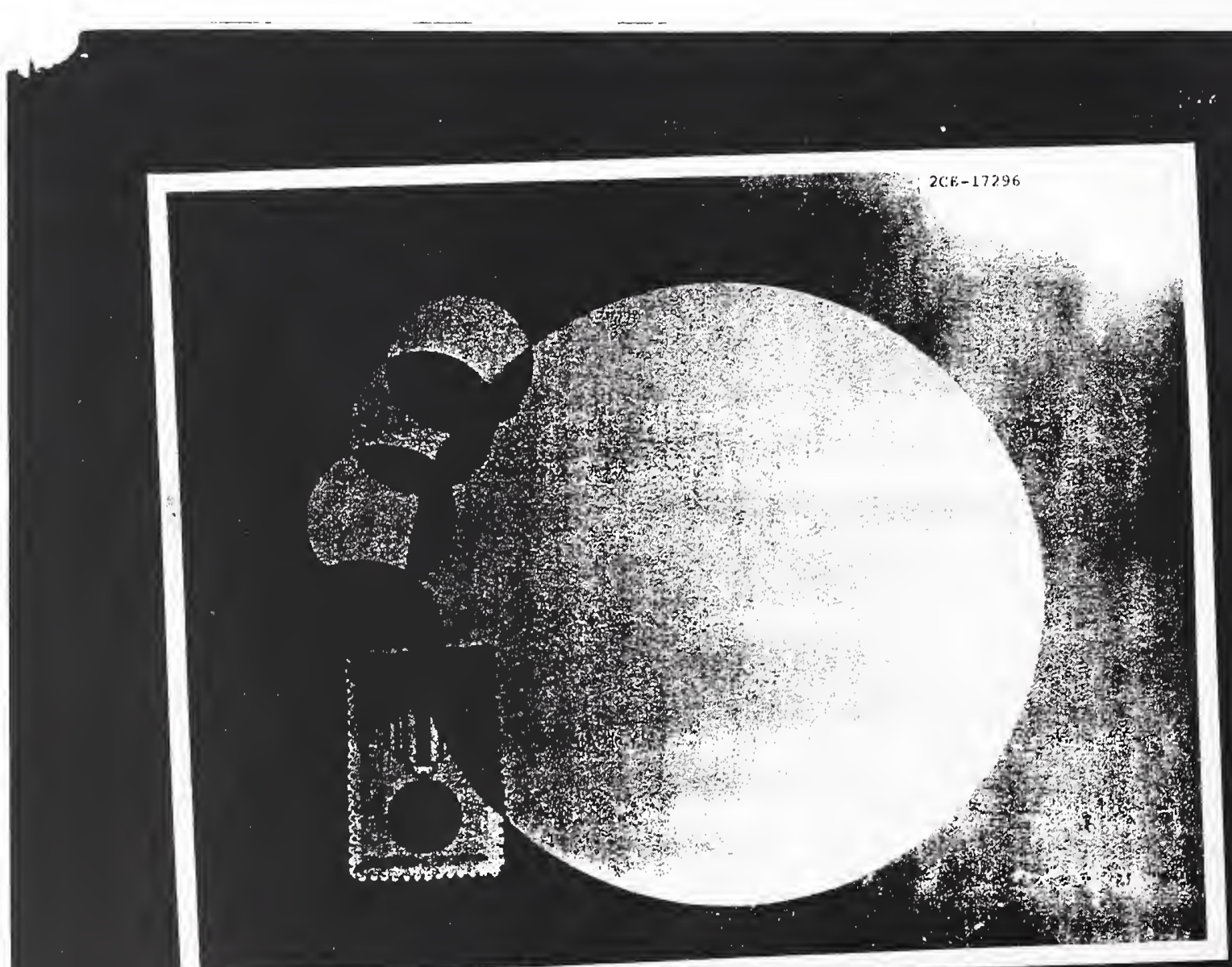


FTIR Absorbance Spectra of CVD Diamond

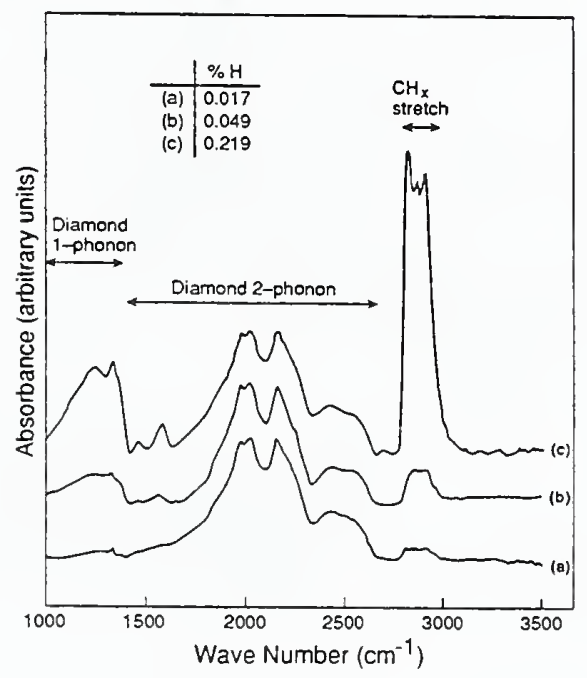

NMR Spectra for CVD Diamond

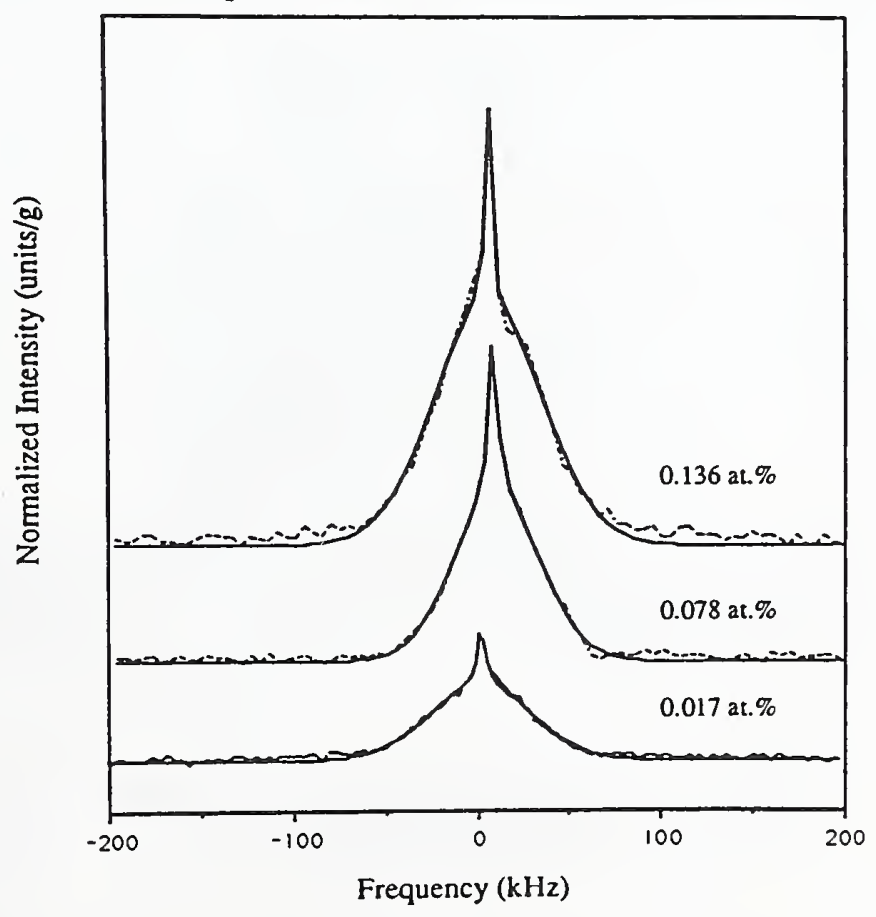


Raytheon

NMR Hydrogen Content vs. Integrated C-H Intensity

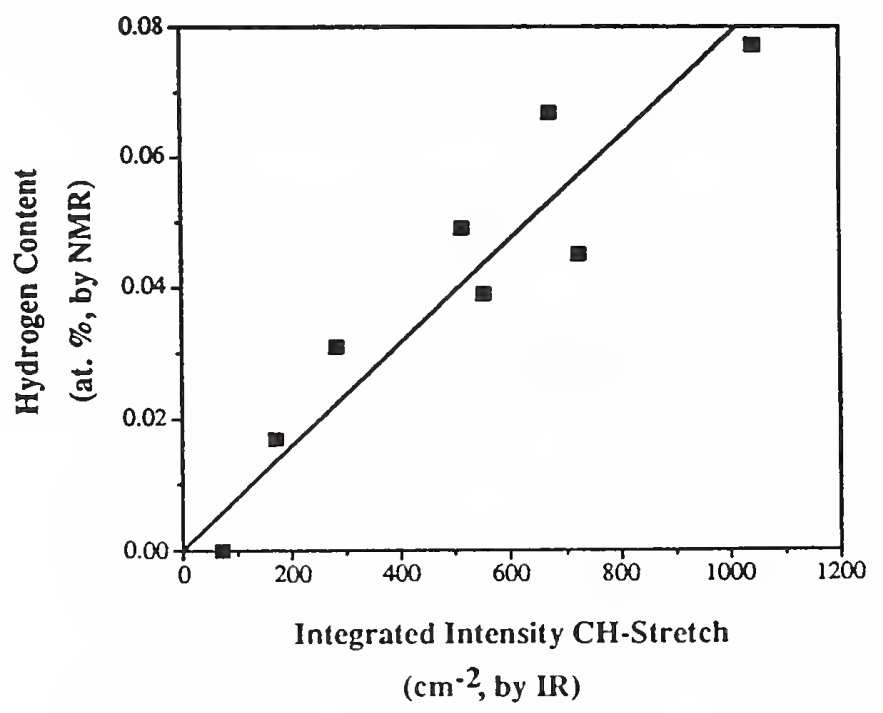

PBN-92-293

\section{C-H Stretch Absorption in CVD Diamond}

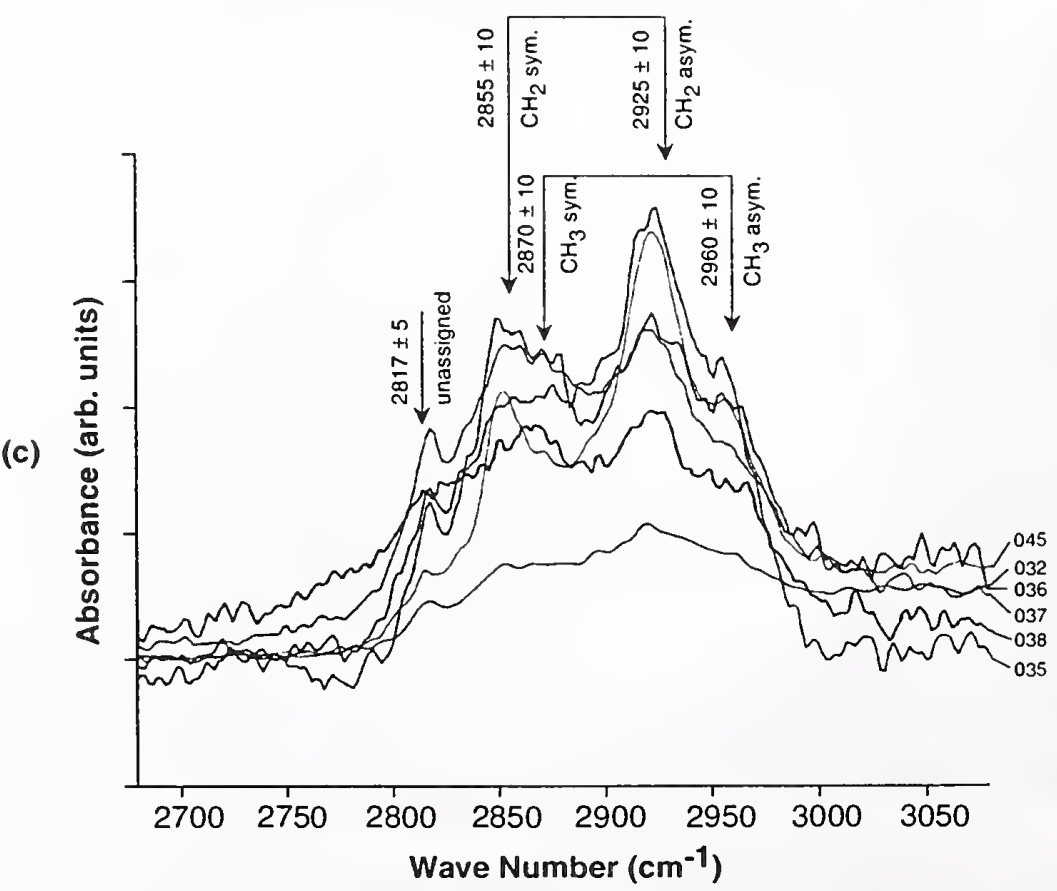




\section{C-H Stretch Absorption in CVD Diamond}

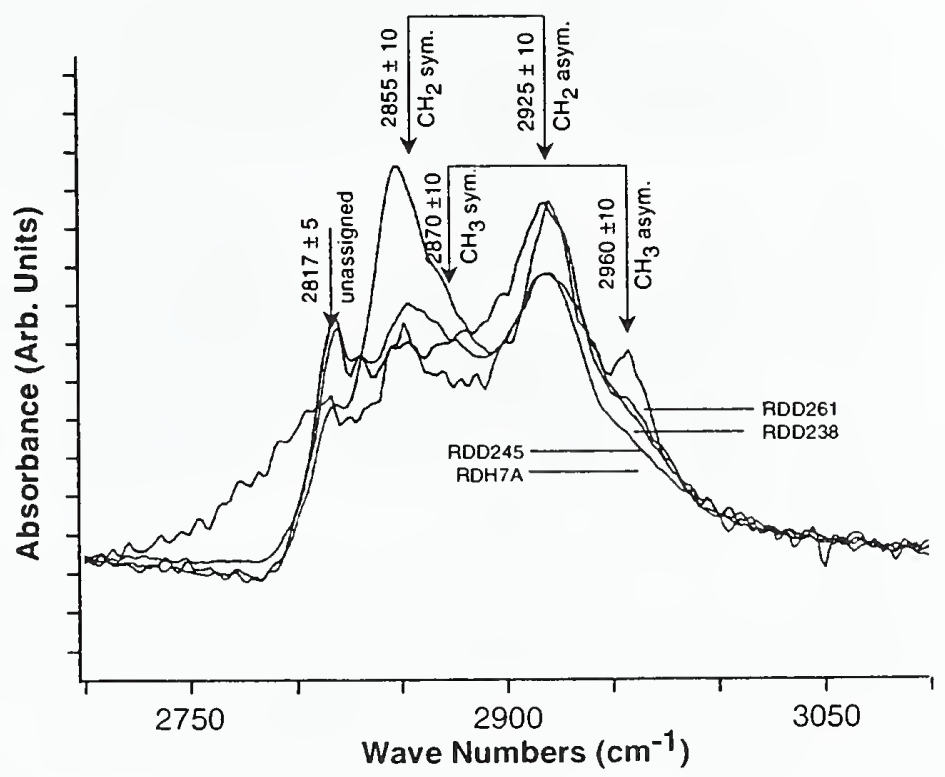

PBN-91-2234

C-H Stretch Absorption in CVD Diamond

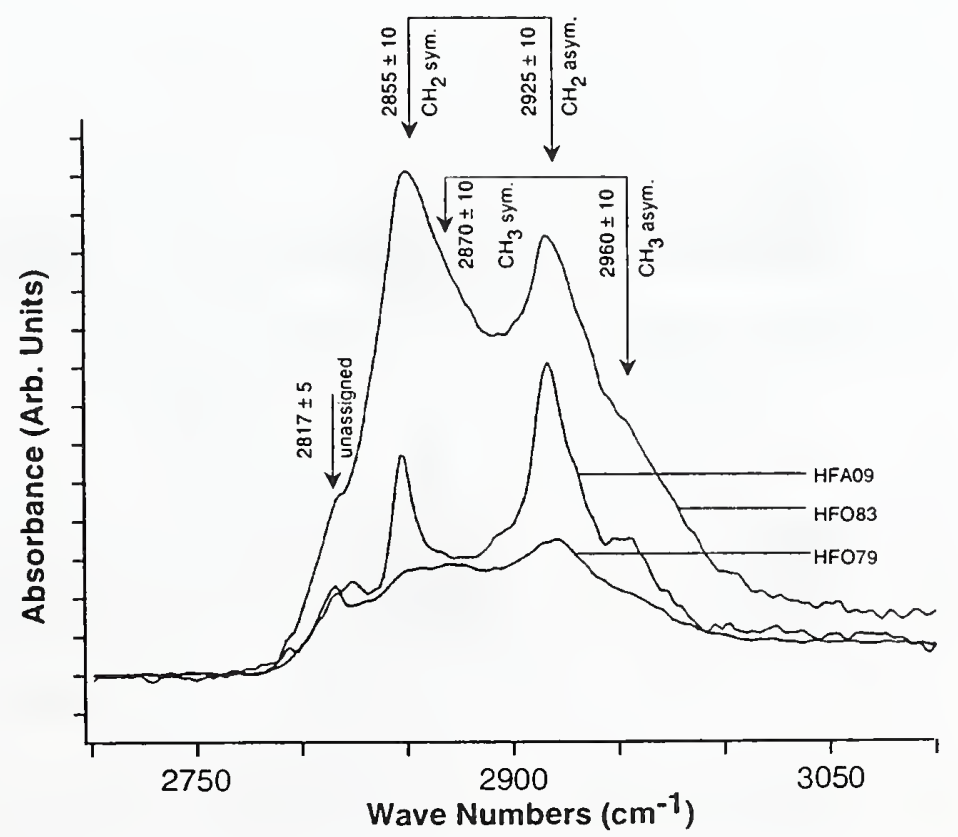


Calibrated FTIR Absorption Spectra of CVD Diamond
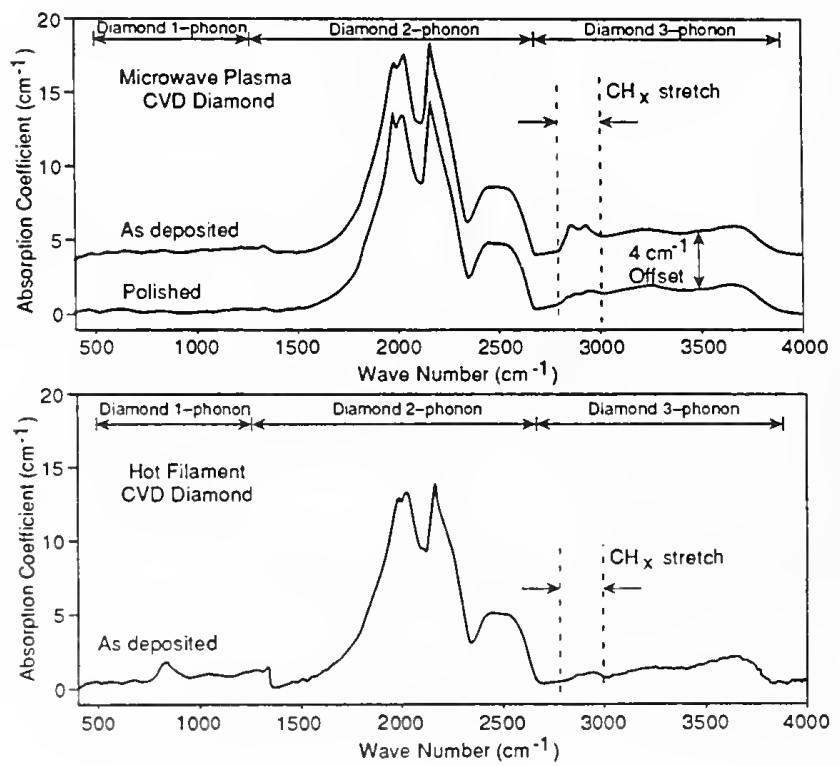

PBN.91.1591

\section{Raman Spectra of CVD Diamond}
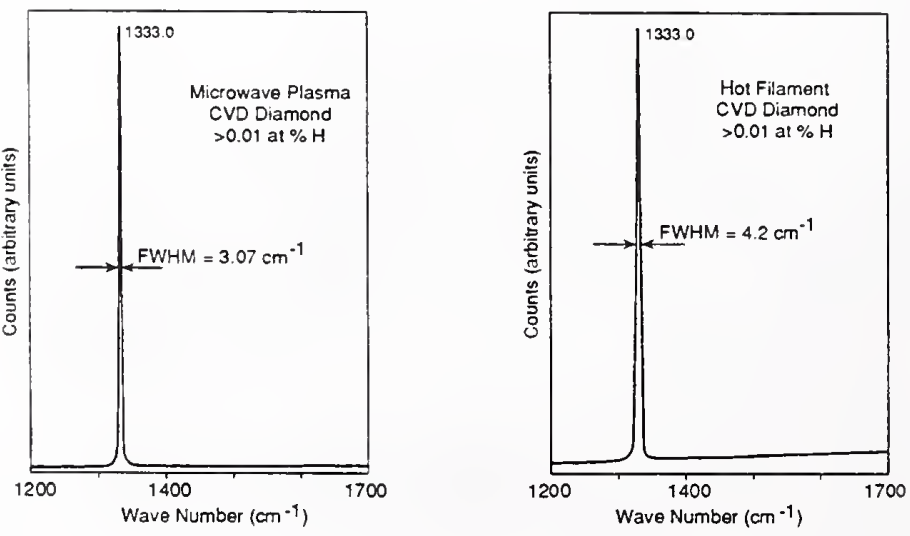
Thermal Conductivity Versus

Temperature of CVD Diamond

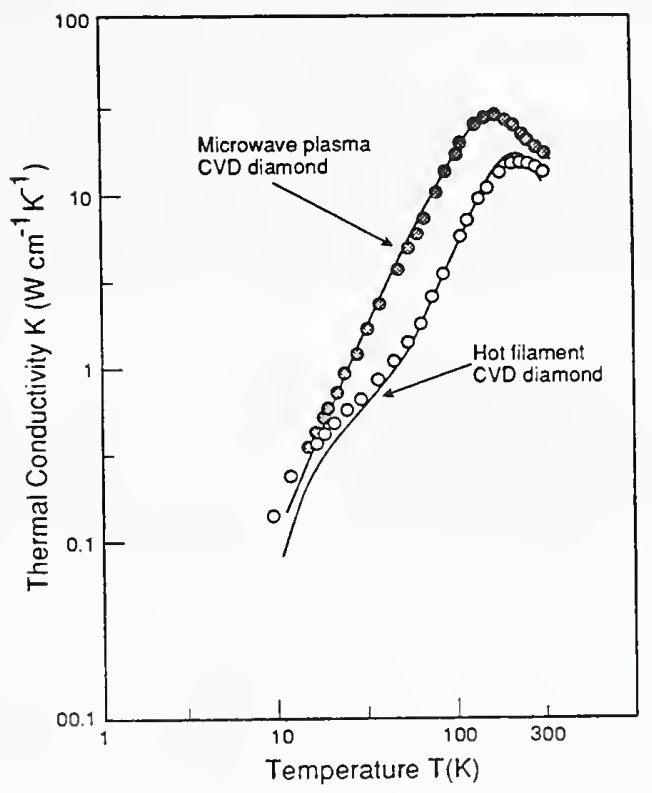

$2 \mathrm{CE}-17358$
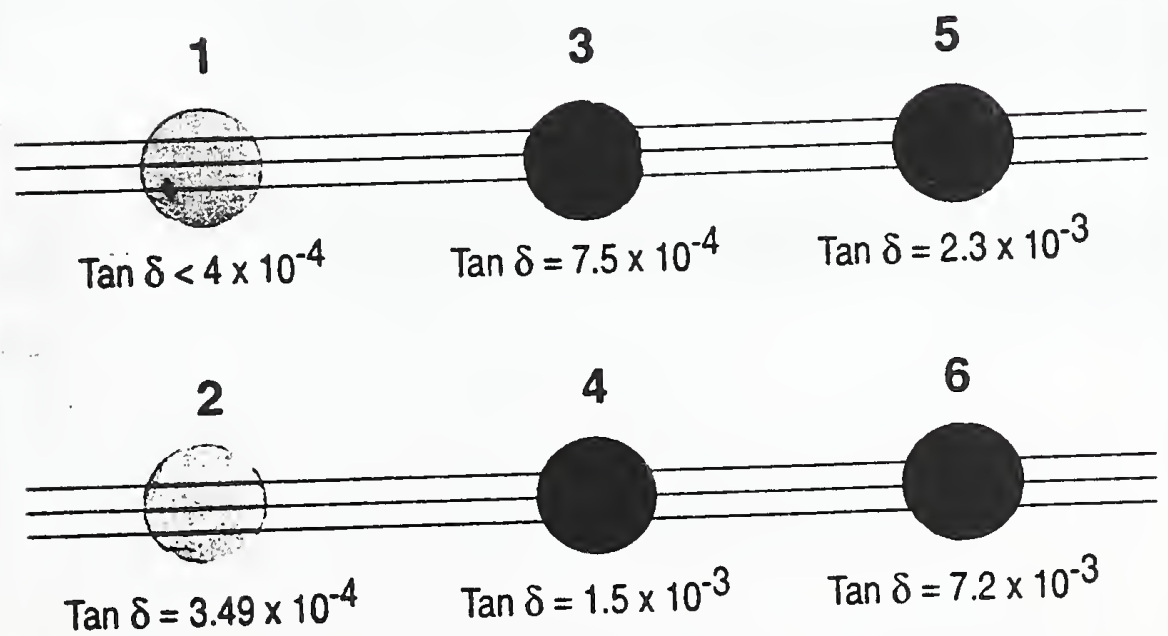


\section{WORKSHOP ON CHARACTERIZING DIAMOND FILMS}

NIST FEB. 27-28, 1992

P. KLOCEK

TEXAS INSTRUMENTS

P.O. BOX 655012 MS 55

DALLAS, TX 75265

(214) $995-6865$

\section{WHY THE POSSIBLE NEED FOR STANDARDS}

- Current limitation of CVD diamond technology to provide adequate size, geometric tolerances, surface quality and statistically valid quantities for some existing "standard tests

Current lack of accepted standard diamond samples to calibrate Raman, IR, fracture toughness, TGA, thermal and electrical 
Define: Application Performance Requirements

Ex. IR missile dome must withstand aero/thermal effects with probability of survival of $\mathbf{9 7 . 9 \%}$

Analyze: Translate performance requirements into material physical property requirements and identify candidate materials

Ex. Flowfield and finite element thermal and structural modeling to determine maximum principal stresses which when combined with probability of survival yields required strength statistics and fracture toughness

Assess:* Characterize material physical properties to assess status vs. requirements.

Ex. Perform biaxial flexure strength tests on statistically valid sample population with precise geometries yielding strengths, Weibull statistics and stress vs. probability of survival, also fractography to determine fracture toughness.

Develop:* Analyze structure or defect/physical property relations to guide development of material

Ex. Fractography yields flaw size, TEM yields structural origin of flaw, $x$-ray yields orientation correlations, morphology, polariscope or Raman or $x$-ray yields residual stress.

* - Possible need for standardized samples, tests and data analysis

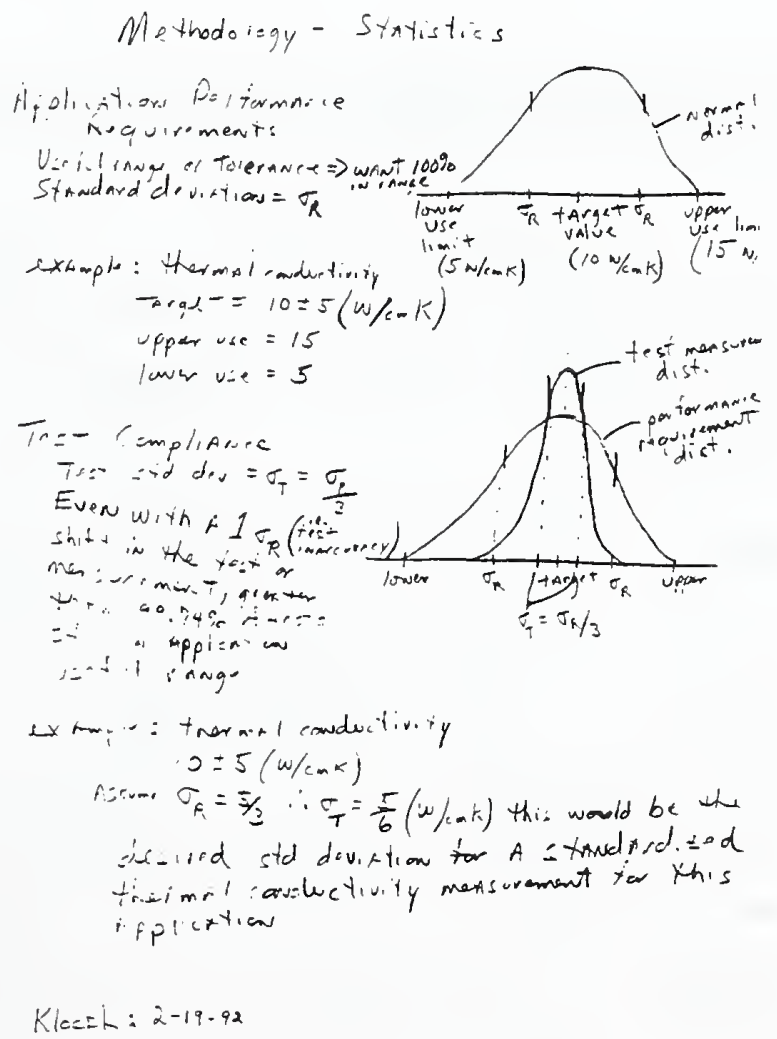


IR MISSILE DOME

\begin{tabular}{|c|c|c|c|}
\hline Recuiremant & $\begin{array}{l}\text { Physical } \\
\text { Preperty }\end{array}$ & $\begin{array}{l}\text { Measurement } \\
\text { Technigues }\end{array}$ & $\begin{array}{l}\text { Data } \\
\text { Anslysis }\end{array}$ \\
\hline $\begin{array}{l}\text { IR Trangmisaion at } \\
\text { High Temperatures }\end{array}$ & $\begin{array}{l}\text { IR absorption } \\
\text { coefficient }\end{array}$ & $\begin{array}{l}\text { IR spect roscopy } \\
\text { spectophotometer, } \\
\text { FTIR, calorimetry }\end{array}$ & $\begin{array}{l}\text { Background subtraction, } \\
\text { multiple reflection } \\
\text { calculation }\end{array}$ \\
\hline Low Emissivity & $\begin{array}{l}\text { IR absorption } \\
\text { coefficient }\end{array}$ & $\begin{array}{l}\text { Same as above, } \\
\text { enissometer }\end{array}$ & Same as above \\
\hline $\begin{array}{l}\text { High Mechanical } \\
\text { Loads }\end{array}$ & $\begin{array}{l}\text { High fracture } \\
\text { toughness. } \\
\text { high Weibull } \\
\text { modulus }\end{array}$ & $\begin{array}{l}\text { Indentation, } \\
\text { biaxial flexure. } \\
3 \text { or \& point } \\
\text { bend }\end{array}$ & $\begin{array}{l}\text { Weibull statistics, } \\
\text { fractography, stress } \\
\text { analysis }\end{array}$ \\
\hline $\begin{array}{l}\text { Thermal Shock } \\
\text { Resigtance }\end{array}$ & $\begin{array}{l}\text { High thermal } \\
\text { conductivity } \\
\text { High fracture } \\
\text { toughness, } \\
\text { High Weibull } \\
\text { modulus, low } \\
\text { thermal } \\
\text { expansion }\end{array}$ & $\begin{array}{l}\text { Thermal shock } \\
\text { test, wind tunnel } \\
\text { test, thermal } \\
\text { diffusivity, } \\
\text { dilatometry, } \\
\text { specific heat }\end{array}$ & Correlation Analysis \\
\hline $\begin{array}{l}\text { High Impact } \\
\text { Registance }\end{array}$ & $\begin{array}{l}\text { High fracture } \\
\text { toughness }\end{array}$ & $\begin{array}{l}\text { Particle imbact } \\
\text { test }\end{array}$ & Correlation Analysis \\
\hline $\begin{array}{l}\text { High Temperature } \\
\text { Stability }\end{array}$ & Low oxidation & $\begin{array}{l}\text { Thermogravimatric } \\
\text { analysis }\end{array}$ & Kinetics Analysis \\
\hline $\begin{array}{l}\text { Imaging, Coherent } \\
\text { wavefront } \\
\text { - Property vs. tem }\end{array}$ & $\begin{array}{l}\text { Index uniformity, } \\
\text { high thermal } \\
\text { conductivity } \\
\text { low dn/dT, dn/dP } \\
\text { rature required. }\end{array}$ & - MTT masurement & Aero-optic Analysis \\
\hline
\end{tabular}

FUNDAMENTAL STRUCTURE OR DEFECT / PROPERTY RELATIONS

DSEG

\section{IECHNIQUE}

Raman

Raman

X-ray

X-ray

X-ray

SEM

TGA

IR

Temporatere

vs. IR

SIMS

NRRA

\section{STRUCTURE / PROPERTY}

\section{BELATION}

Structural integrity

Residual Stress

Orientation

Residual Stress

Purity

Morphology

Oxidation

Dofect identification

Intrinsic ve. Extrinsic

fechure identification

Impurtion

Impentives
DATA

Peak FWHM / Spectra

Peak shift

Peak ratios

Peak shift

Additional lines/spectra

Gnetices

Additional lines / spectra

Additional lines/spectra and dependencies

Concentrations

Concentrations

- All need standard samples for calibration not juot diamond but defective diamond 


\section{OPTICAL PROPERTIES}

Transmission / Absorption Coefficients

Sample preparation: Surface Roughness, Parallelism, Flatness

Measurement: External transmittance (spectrophotometer or FTIR), calibration standard

Data Analysis:

Without scattering - multiple reflection calculation of absorption coefficient knowing thickness and index

With scattering - scattering baseline subtraction then multiple reflection calculation or $(-1 n)$ transmittance then scattering baseline substraction then divide by thickness

Absorption analysis: Validate vs. laser calorimetry, compare with "standard" diamond

Intrinsic Absorption - spectral and coefficient comparison, temperature dependence comparison

Extrinsic Absorption - defect identification vs. "standard" diamond, concentration vs. coefficient correlation, spectral identification vs. "standard" diamond

Issue: Are defects in natural diamond the same in CVD diamond (made by various processes)?

\section{INFRARED OPTICAL COMPONENTS SPEGIFICATIONS}

\section{- SURFACE QUALITY (Scratch \#/dig \#)}

$80 / 50$ within the clear aperture $120 / 80$ outside the clear aperture in accordance with MIL-C-48497A

Ex. 80/50 means that no scratch on the surface can be wider than $80 \mathrm{um}$ and no dig can have a diameter greater than $50 \mathrm{um}$

- optical finish

Max of 1 microinch surface roughness

- PARALLELISM/THICKNESS

Dome concentricity to within $.0003^{\text {" FIR }}$

Thickness tolerance $.002^{z}$

- WAVEFRONT ERROR (flatness)

.12 wave at $10.6 \mathrm{um}$ ( 1 fringe surface power and irregularity at 6328A)

- CHAMFER

Edges have protective chamfer of $0.060^{*}$

- EDGE CHIPS

Sum of edge chip length cannot exceed $30 \%$ of component perimeter. Chips not to extend in clear aperture. Chip size less than $.02^{\mathrm{z}}$. 


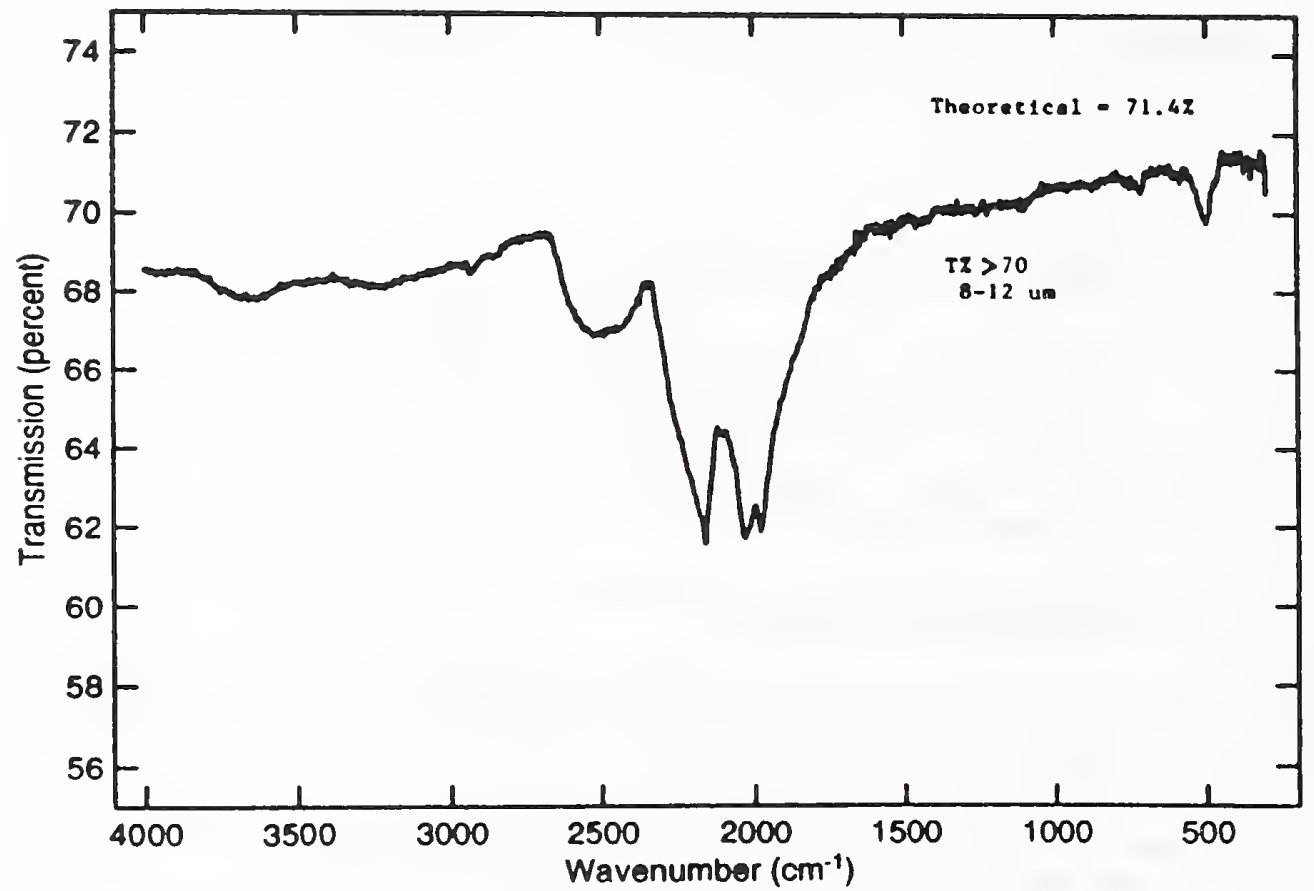

Figure 11. Transmission Scan of CVD Dianond of Figure 10

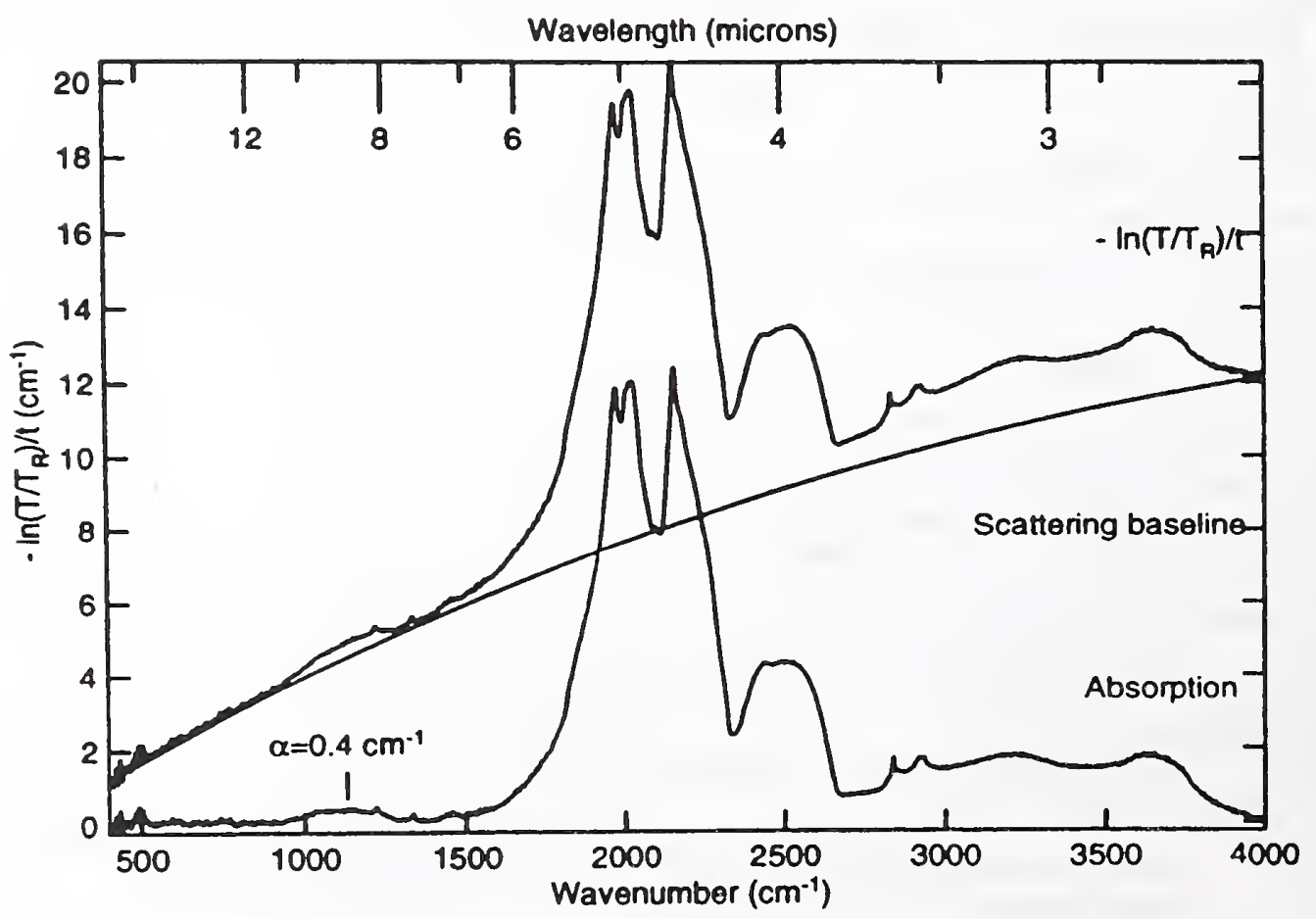

Figure 7. Method of Determining Absorption Coefficient Spectrum 


\section{MECHANICAL PROPERTIES}

\section{STRENGTH / FRACTURE TOUGHNESS}

Sample Preparation: surface roughness, parallelism, flatness, edges, statistically valid sample population, size

Measurement: biaxial flexure (ball on ring, ring on ring), flexure ( 3 or 4 point bend

Data Analysis: statistics - avg. and std. dev., Weibull statistics - modulus and survivability vs. stress

Fracture Analysis: fractography yields flaw size and fracture toughness, morphology / grain size / orientation/residual stress etc. possible toughening mechanisms

Flaw Analysis: source of flaw, propagation characteristics (intra granular, inter granular, fast or slow, etc.)

Issue: Are flaws in CVD diamond made in one process the same as another process?

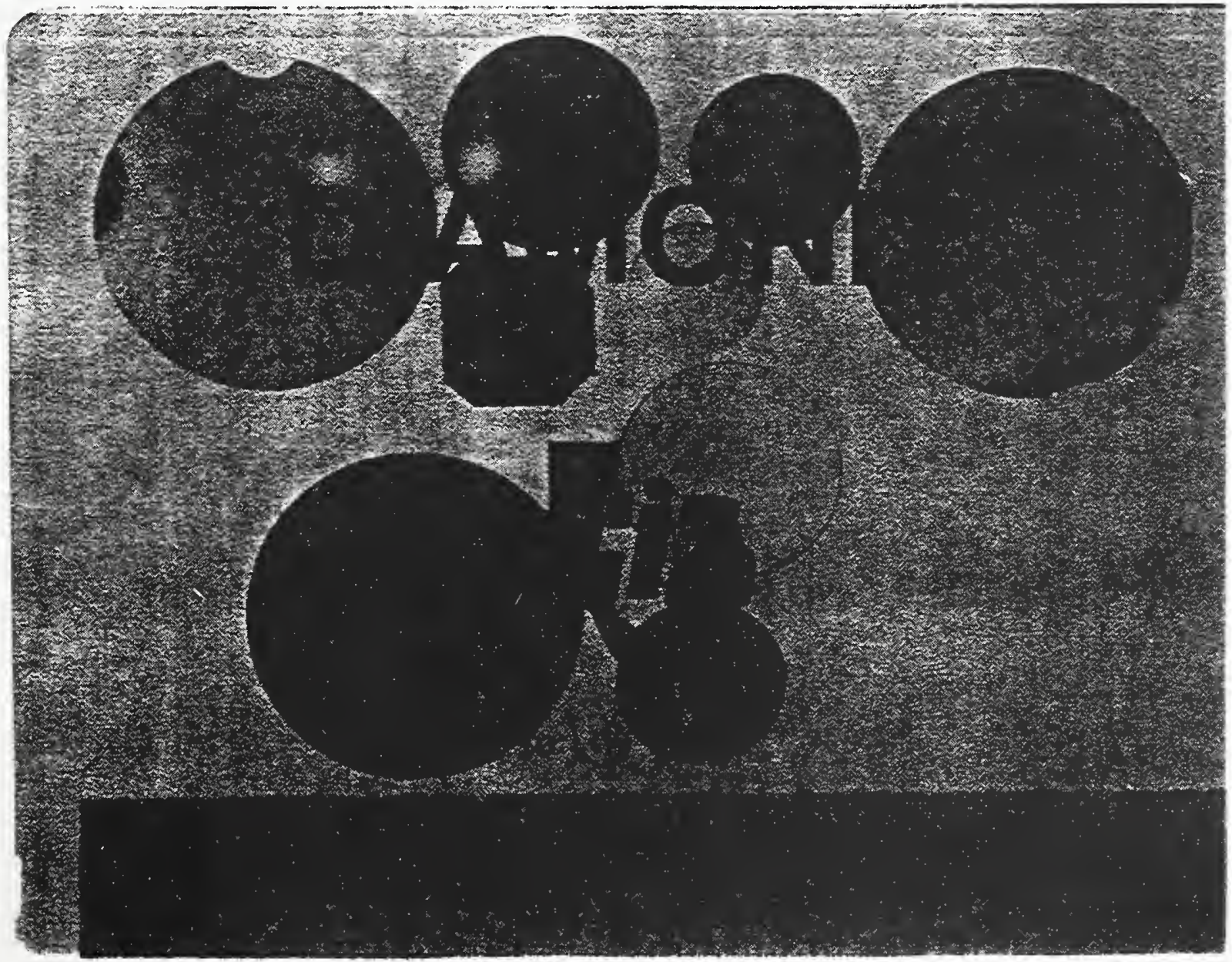




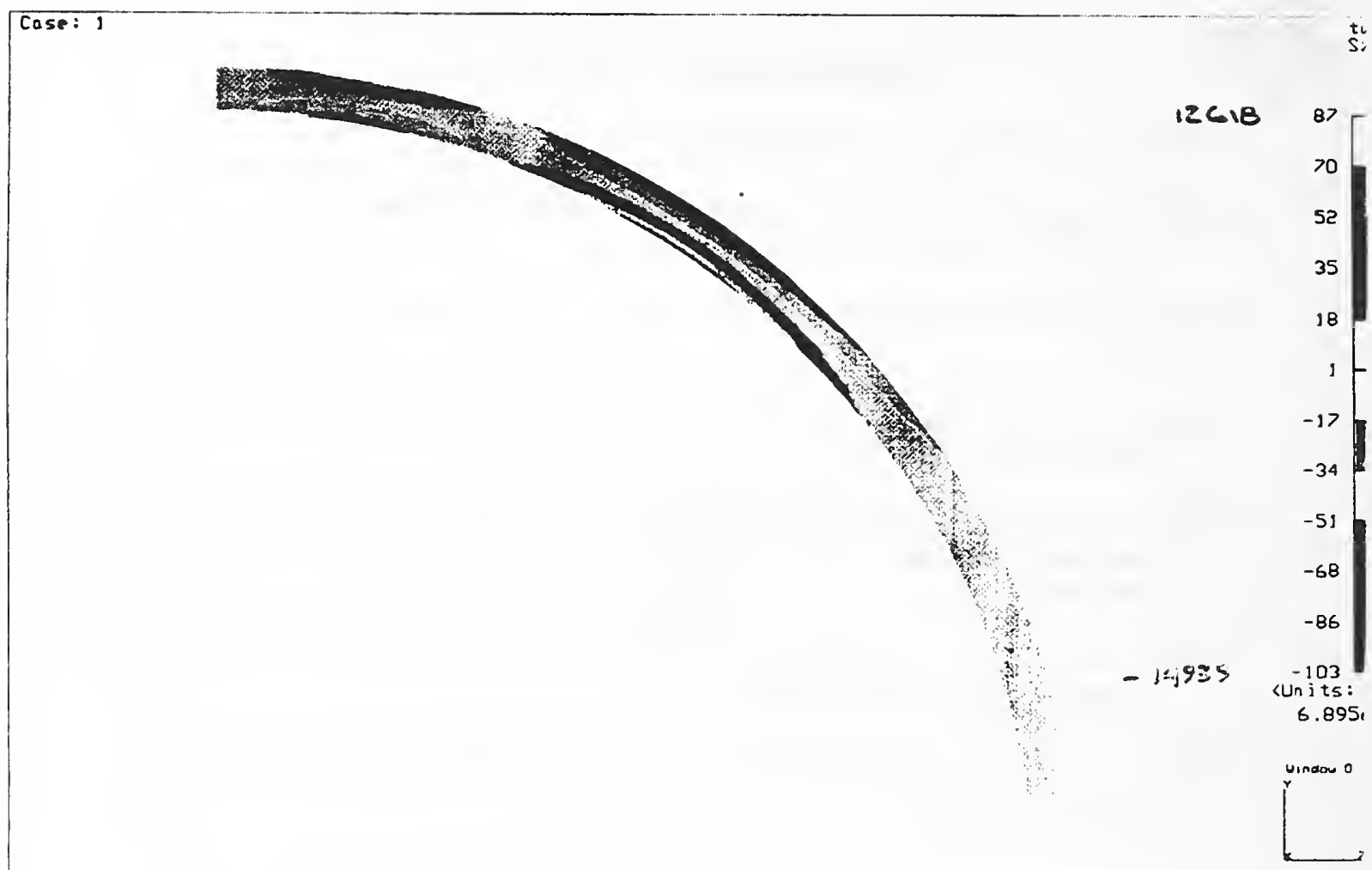

\section{Strength Mleasurements}

Issue: Sample sive And loading should represent Application

$$
\begin{aligned}
& \text { Binxinl Flexure } \\
& \hline \text { Ball on Ring } \\
& \text { No edge londing } \\
& \text { SAmple dise } \\
& \text { Ring on Ring } \\
& \text { No edga lending } \\
& \text { Sample dise }
\end{aligned}
$$

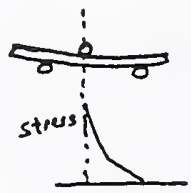

$\because$
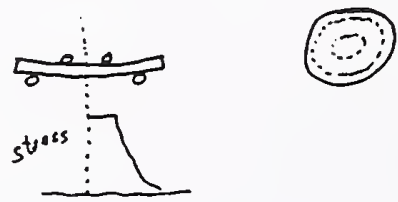

Flexure

$$
\begin{aligned}
& 3 \text { or } 4 \text { Point Bond } \\
& \text { Edge Loading } \\
& \text { Sample bar }
\end{aligned}
$$
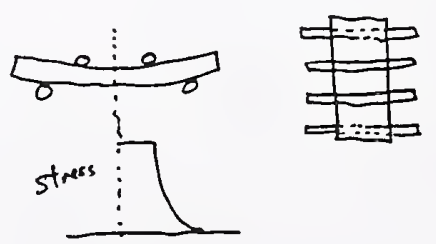


\section{NEED FOR DIAMOND STANDARDS - SUMMARY}

WIDE RANGE OF APPLICATIONS DEMAND VARIOUS OPERATIONAL PERFORMANCE

Need for

- Requirement for testing of various physical properties

wide range of

- Test methods and sample geometries may need to vary

standard

testing

for the same physical property for different applications

i.e. mechanical

\section{DIFFERENT FABRICATION PROCESSES OF CVD DIAMOND}

Need for

standard

- Varying sample geometric limits

sample

- Possible difference in defects from process to process

preparation

- Varying "quality" in sample preparation i.e., cutting, polishing

- Potential difficulty in assessing process status vs. application

\section{DEFECT IDENTIFICATION ESSENTIAL FOR DEVELOPMENT}

Need for

- Ex. Is hydrogen defect the same from process to process

standard

- Wide variety of characterization techniques

measurement

techniques and

standard or

calibration samples 


\title{
STANDARDIZED DIAMOND FILM CHARACTERIZATION FOR THE COMMERCIAL MARKET
}

\author{
Kevin Gray
}

Norton Dianond Films

STANDARDIZED DIAMOND FILM CIIARACTERIZATION Diamond Film Technology Insertion Issues

- What are available sizes, shapes, and (quantities?

- Will the diamond meet performance requirennents?

- What will it cost? 


\section{STANDARDIZED DIAMOND FILM CHARACTERIZATION \\ Diamond Performance Verification}

- Are the manufacturers' claims believable?

- Are independent confirmations available?

\section{STANDARDIZED DIAMOND FILM CIIARACTERIZATION \\ Benefits of Standards}

- Traceability of manufacturers' clains and methods

- Provides independent evaluations

- Lends credibility to CVD diamond industry

- Enliances consumer confidence 
- Characteristics of the Ideal Standard:

Accuracy and reproducibility

Non-destructive technique

Widely available

Provides quick feedback (ease of use for QC)

Ease of sample preparation

Trade-offs

\section{STANDARDIZED DIAMOND FILM CHARACTERIZATION \\ Development of a Standard}

- Blind Round Robin testing:

Anonymity essential for sample providers and measurement labs

Clearing house for samples-codes sample and lab names

Many labs measure samples

Public release of all data without attribution to lab or sample

Sample providers know only their sample codes

Sample providers can compare their material with others

Measurement labs know only their lab code(s) 
STANDARDIZED DIAMOND FILM CHARACTERIZATION

Development of a Standard

- Blind Round Robin testing: continued

Labs can compare their results with others

This data feeds discussions of possible standards

STANDARDIZED DIAMOND FILM CHAIACTERIZATION

Round Robin Testing Example - Public Data

Sample

\begin{tabular}{lccc}
\hline Lab & A & B & C \\
\hline 1 & 6.9 & 13.6 & 10.1 \\
2 & 7.2 & 13.4 & 10.3 \\
3 & 4.1 & 15.0 & 7.6 \\
4 & 10.9 & 17.0 & 14.7 \\
\hline
\end{tabular}

Lab 1 Method:

Lab 2 Method: 
STANDARDIZED DIAMOND FILM CHARACTERIZATION

Round Robin Testing Example - Actual Data

\begin{tabular}{lccc} 
& \multicolumn{3}{c}{ Sample } \\
\hline \multicolumn{1}{c}{ Lab } & ABC & Diamond & Diamonds \\
Diamond & CVD Inc. & R Us \\
Sample 1 & Sample 1 & Sample 3 \\
\hline Prestigious U. & 6.9 & 13.6 & 10.1 \\
Govt. Lab & 7.2 & 13.4 & 10.3 \\
Diamond CVD Inc. & 4.1 & 15.0 & 7.6 \\
Comm. Lab & 10.9 & 17.0 & 14.7 \\
\hline
\end{tabular}

Lab 1 Method:

Lab 2 Method: 


\title{
NEEDS FOR ADDITIONAL TESTING \\ DEVELOPMENT AND STANDARDS
}

\author{
Michael Drory \\ Crystallume \\ 125 Constitution Drive \\ Menlo Park, CA 94025
}

Crystallume

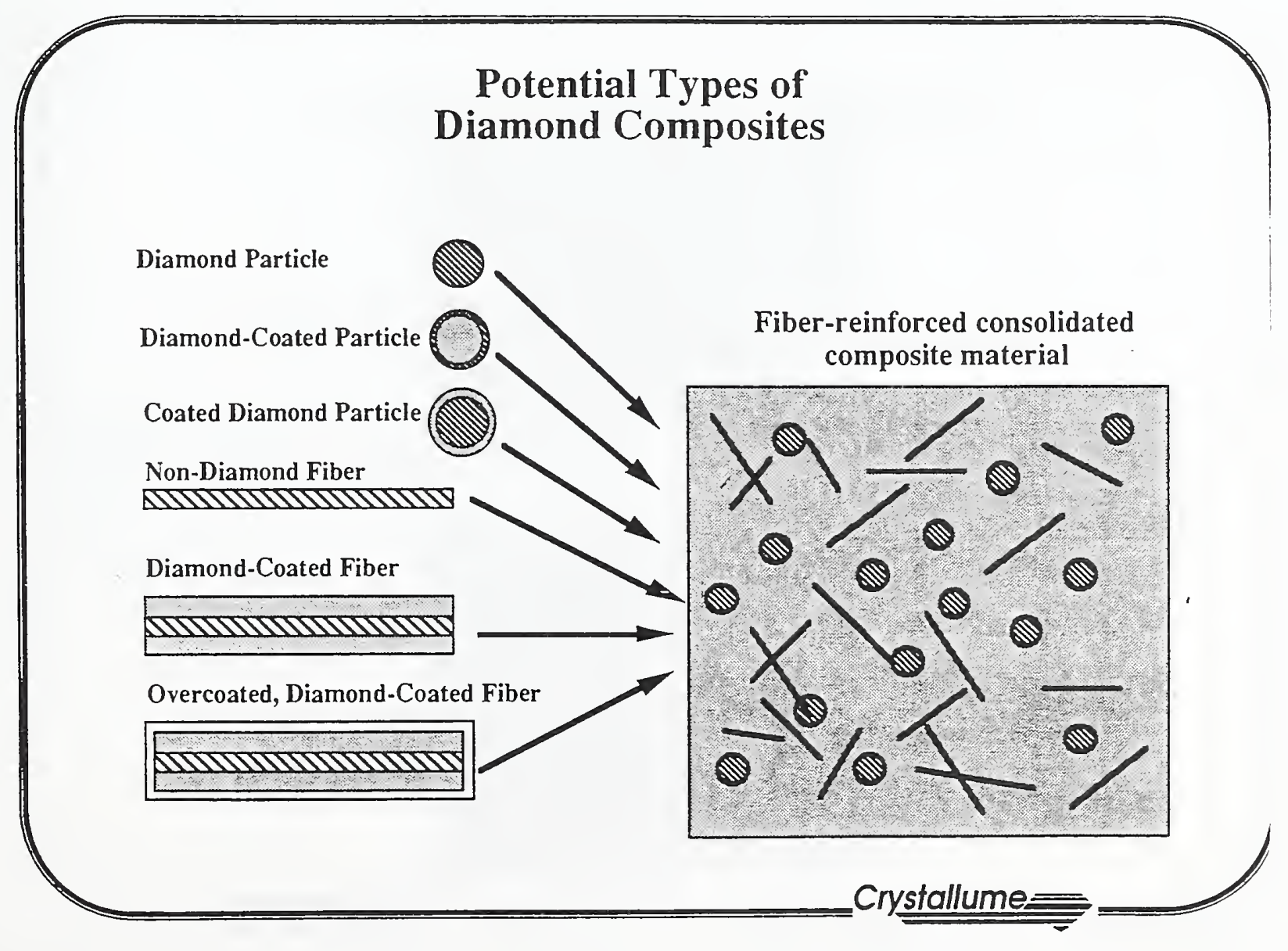




\section{DIAMOND CERAMICS}

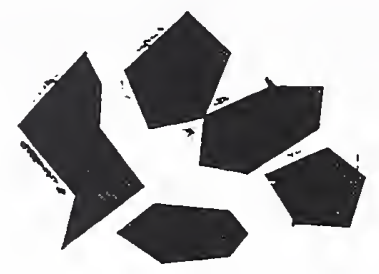

Unconsolidated,

Loose-Packed

SiC Particles

CVD-Diamond

Consolidated

SiC/Diamond

Ceramic

Crystallume

\section{DIAMOND CERAMICS FOR MCM}

APPROACH:

\section{CHEMICAL VAPOR INFILTRATION (CVI)}

\section{DIAMOND}

PARTICLES

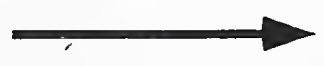

PECVD

DIAMOND

(MICROWAVE)
CONSOLIDATED SUBSTRATE

LARGE AREA SUBSTRATES WITH THE HIGHEST THERMAL CONDUCTIVITY 


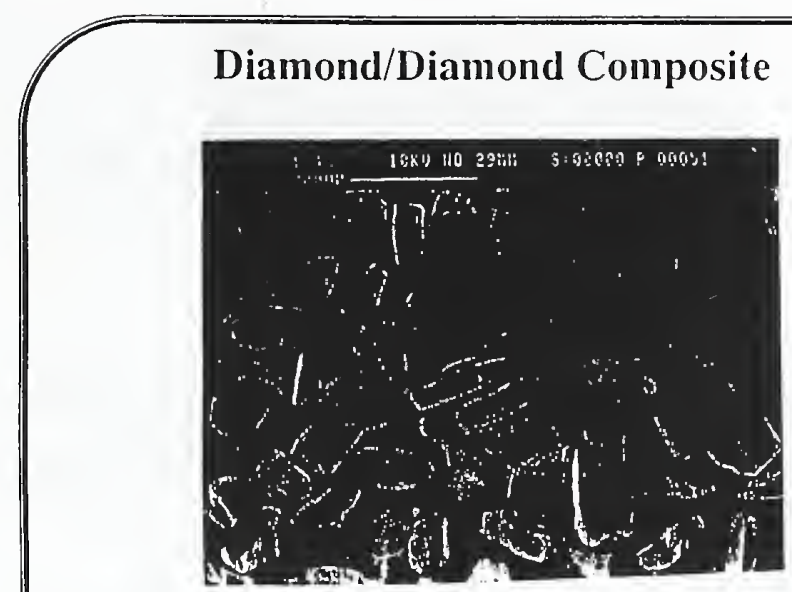

Diamond Particles, Pre-Consolidation

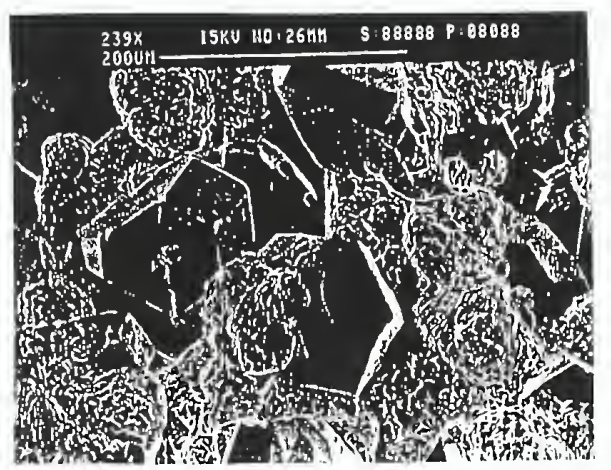

Diamond Particles, Intermediate Consolidation Crystallume

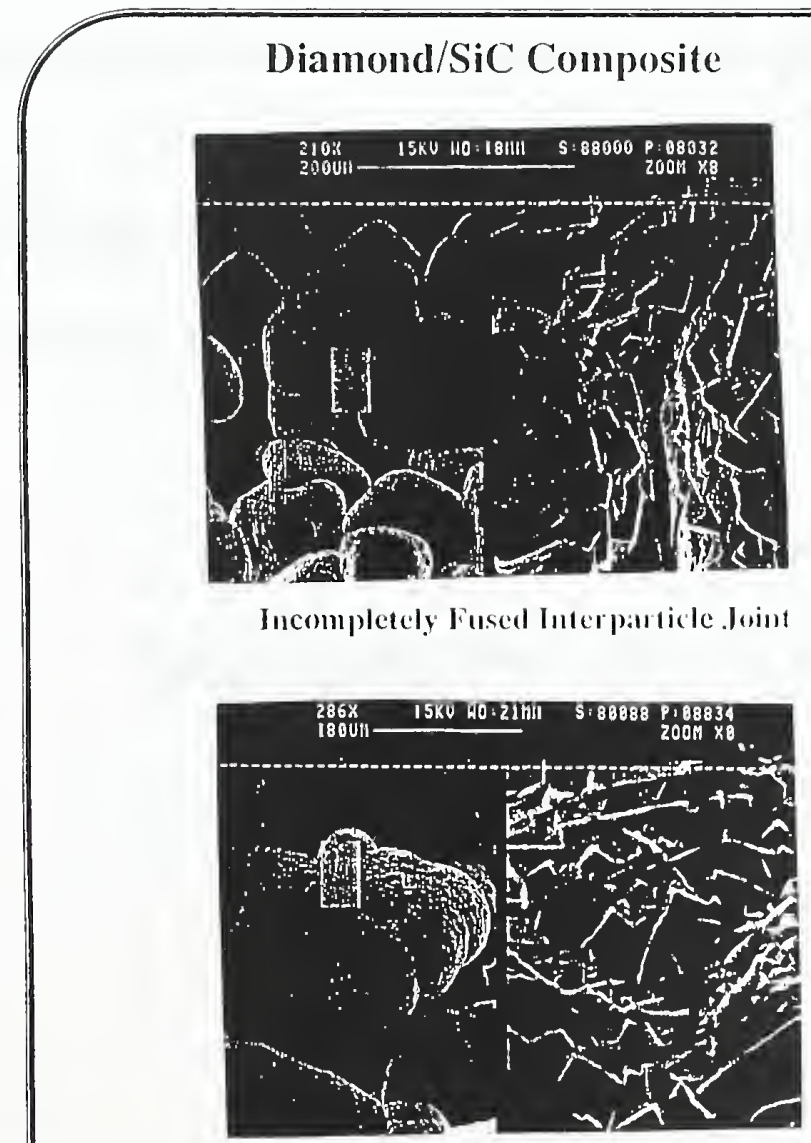

Fused Interparticle Joint 


\section{STRENGTH MEASUREMENTS OF CVD DIAMOND}

\section{BURST TESTING}

Windishmann, et. al. 1991 Proceedings New Diamond Science and Technology Conference

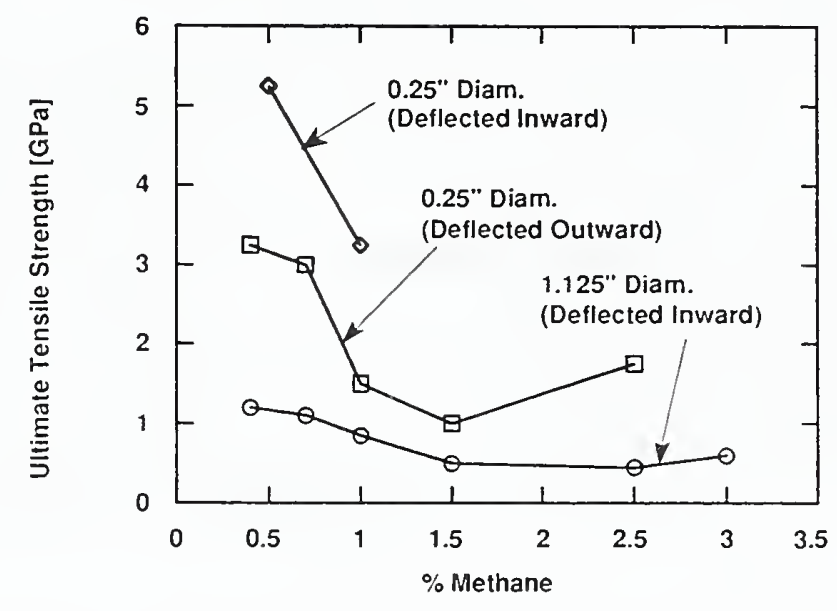

Crystallume

NEED FOR FURTHER TESTING DEVELOPMENT

BURST TESTING

- Buckling

- Size Effects

- Analysis is incomplete 
WORKSHOP on CHARACTERIZING DIAMOND FILMS

FRIDAY, FEBRUARY 28, 1992

\section{ROCKWELL INTERNATIONAL CORPORATION}

SANDOR HOLLY

WORKSHOP on CHARACTERIZING DIAMOND FILMS

FRIDAY, FEBRUARY 28, 1992

DIAMOND APPLICATION AREAS

- TRIBOLOGICAL (MECHANICAL)

- THERMAL (HEAT EXCHANGERS)

- OPTICAL (WINDOWS) 


\section{WORKSHOP ON CHARACTERIZING DIAMOND FILMS}

FRIDAY, FEBRUARY 28, 1992

8:45 AM - 10:45 AM

\section{THE NEED FOR STANDARDS}

- J. W. MITCHELL

- MICHAEL DRORY

- KEVIN GRAY

- SANDOR HOLLY

- PAUL KLOCEK

- CLIFFORD J. ROBINSON
- AT\&T BELL LABORATORIES

- CRYSTALlume

- NORTON COMPANY

- ROCKWELL INTERNATIONAL

- TEXAS INSTRUMENTS

- RAYTHEON

\section{WORKSHOP on CHARACTERIZING DIAMOND FILMS}

FRIDAY, FEBRUARY 28, 1992

\section{THE NEED FOR STANDARDS}

- NEEDED: RELIABLE MIATERIAL CHARACTERISTICS DATA IN DESIGN

- MANY DISCIPLINES INVOLVED

- MANY DIFFERENT DEFINITIONS OF QUANTITIES AND PROPERTIES

- MANY TYPES OF MEASUREMENT TECHNIQUES USED

- MANY PARAMETERS THAT INFLUENCE DATA VALUE AND ACCURACY

- RESEARCHERS WITH WIDELY VARYING BACKGROUNDS \& EXPERIENCE 
WORKSHOP on CHARACTERIZING DIAMOND FILMS

FRIDAY, FEBRUARY 28, 1992

\author{
THE NEED FOR STANDARDS
}

\title{
PROPOSED APPROACH
}

- FORM SPECIALTY GROUPS

- START WITH DEFINITIONS OF SIMPLE CONCEPTS AND CHARACTERISTICS

- FOCUS ON PRACTICAL ASPECTS OF STANDARDS

- TRY TO IDENTIFY STANDARDS TO WHICH DATA CAN BE RELATED

- PROMOTE EXCHANGE OF INFORMATION (MEETINGS, PUBLICATIONS)

- DATA BANK OF CHARACTERISTICS, DATA BANK OF LITERATURE 
Appendix F.

\section{List of Attenders}


Workshop on Characterizing Diamond Films

National Institute of Standards and Technology

February 27-28, 1992

\section{Final Participants List}

Charles P. Beetz

Advanced Technology Materials

7 Commerce Dr.

Danbury, CT 06810

David Black

NIST

Gaithersburg, MD 20899

David Cahill

University of Illinois

1101 W. Springfield Ave.

185A CSL

Urbana, IL 61801

Clark Cooper

United Technologies Research Ctr.

400 Main Street

MS 129.22

East Hartford, CT 06108

Michael Drory

Crystallume

125 Constitution Dr.

Menlo Park, CA 94025

Robert A. Erck

Argonne National Lab

9700 South Cass Ave.

Argonne, IL 60439

Edward Farabaugh

NIST

Gaithersburg, Md 20899

Albert Feldman

NIST

Materials Bldg., Rm A329
John Graebner

AT\&T Bell Laboratories

600 Mountain Ave.

MH1D157

Murry Hill, NJ 07974

Kevin Gray

Norton Company

Goddard Rd.

Northboro, MA 01532

John Gudas

NIST

Gaithersburg, MD 20899

Sandor Holly

Rockwell International

6633 Canoga Ave.

Canoga Park, CA 91304

Richard Kant

Naval Research Lab.

4555 Overlook Ave.

Washington, DC 20375

George Kim

Edge Technologies Inc.

4455 West 62nd St.

Indianapolis, IN 46268

Claude A. Klein

Raytheon - Research Division

131 Spring St.

Lexington, MA 02173

Paul Klocek

Texas Instruments

PO Box 655012 
Pao-Kuang Kuo

Wayne State University

666 W. Hancock

Physics Department

Detroit, MI 48201

George Lamaze

NIST

Gaithersburg, MD 20899

Grant Lu

Norton Company

Goddard Rd.

Northboro, MA 01532

James A. McCaulley

Hoechst Celanese Corp.

86 Morris Ave.

Summit, NJ 07901

Carl McHargue

University of Tennessee

Middle Dr.

Rm 121, Perkins Hall

Knoxville, TN 37996-2000

J.J. Mecholsky

University of Florida

256 Rhine Hall

Gainesville, FL 32611

James W. Mitchell

AT\&T Bell Laboratories

600 Mountain Ave.

Room 1D-239

Murray Hill, NJ 07974

Lawrence Mizerka

US Army

AMSEL-RD-NV-LPD

Ft. Belvoir, VA 22060

Donald Morelli

General Motors Research Lab.

30500 Mound Rd., Box 9055

Warren, MI 48090
David Pickrell

Diamonex

7150 Windsor Dr.

Iron Run Corp Ctr

Allentown, PA 18106

Lawrence H. Robins

NIST

Gaithersburg, MD 20899

Jim Russell

Diamond Depositions

710 Easton Ave. \#C

Somerset, NJ 08873-1855

Robert L. Thomas

Wayne State University

666 W. Hancock

Rm 281

Detroit, MI 48202

John Trombetta

Texas Instruments

PO Box 655012/MS 55

Ronald Tye

Sinku-Riko Inc. 105 York St.

Kennebunk, ME 04043

Jan W. Vandersande

Jet Propulsion

4800 Oak Grove

Pasadena, CA 91109

Lanhua Wei

Wayne State University

666 W. Hancock

Physics Dept

Detroit, MI 48201

Brad Williams

General Electric - CRD

1 River Rd.

K-1-3B16

Schenectady, NY 12309 
Robert Young

Westinghouse STC

1310 Beulah Rd.

Pittsburgh, PA 15235 


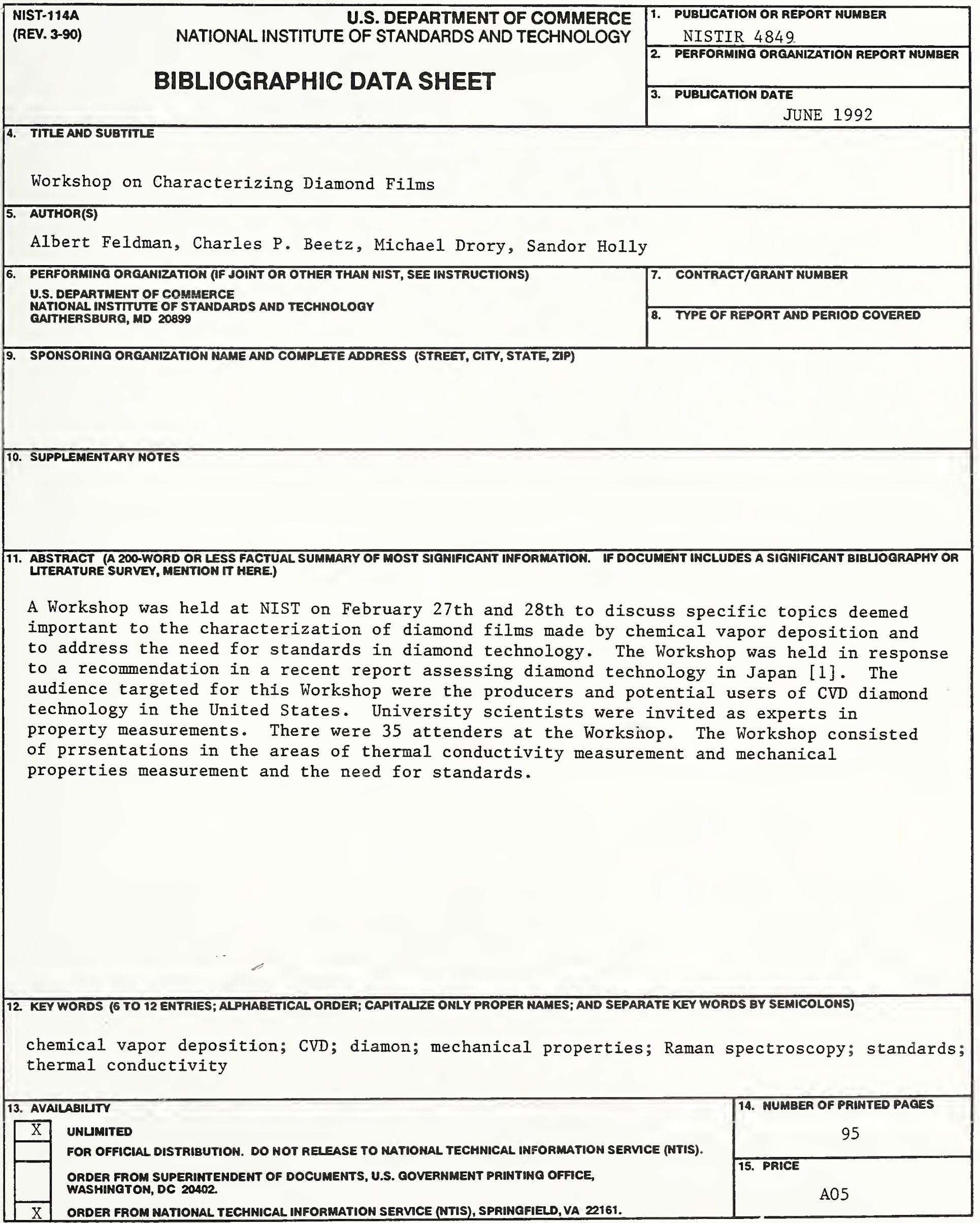




